\title{
MILP model for long-term energy mix planning with consideration of power system reserves
}

\author{
Michal Wierzbowski $^{\text {** }}$, Wojciech Lyzwa ${ }^{\text {a }}$ Izabela Musial ${ }^{\mathrm{a}}$
}

${ }^{a}$ Lodz University of Technology, 90-924 Lodz, Poland

\begin{abstract}
The purpose of this paper is to present the novel long-term energy mix optimization model $e M i x$, which takes into account daily requirements of power system operation (primary, secondary and tertiary reserve) and how should they react to increasing RES penetration.

Until now there has been no computational effective, long-term optimization model of energy mix with individual representation of power generating assets that allows for RES development incorporation and consider the daily requirement of power system operation. Existing unit commitment models, although comprehensive, are not appropriate for long-term, large-scale problems because of computational limitations. The $e M i x$ links long-term planning (investments) with shortterm requirements of power system operation reserves (primary, secondary, tertiary) provided by dispatchable units. Additionally, development of the RES introduces stronger requirements to the reserve's level in order to maintain the flexibility of the power system operation. This relation has significant impact on the final energy mix and was modeled in the eMix. The costs are calculated annually for each individual unit (given to the application of Mixed Integer Linear Programming), to reflect the real conditions of energy sector operation, where annual repayment of loans, amortization as well as operation and maintenance costs are applied. eMix is also fully scalable and allows for freely definable interval and horizon of the calculation.

To prove the quality of presented model, the authors calibrated it with the data from Polish power system for different scenarios. Results indicate that the consideration of financial costs and required reserves increase the reliability of the optimization outcomes.
\end{abstract}

Keywords: generation expansion planning; energy mix ; optimization, MILP, energy system modelling

${ }^{*}$ Corresponding author. Tel.: +48 503033225

E-mail address: michal.wierzbowski@p.lodz.pl 
TABLE OF CONTENT

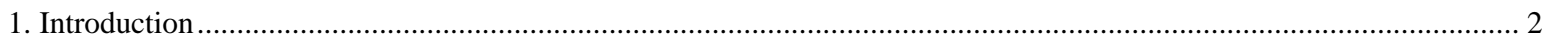

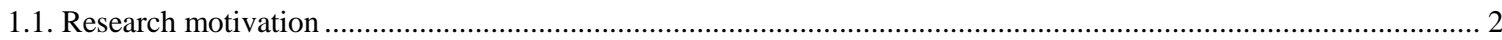

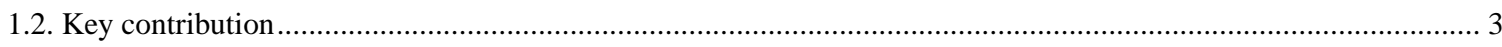

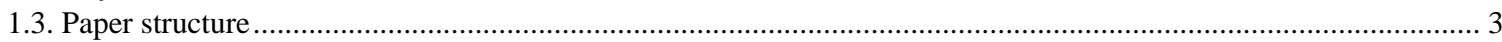

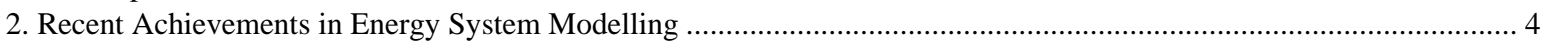

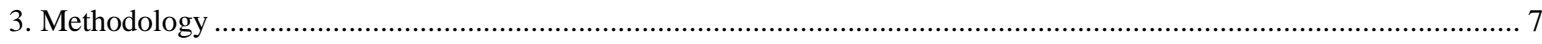

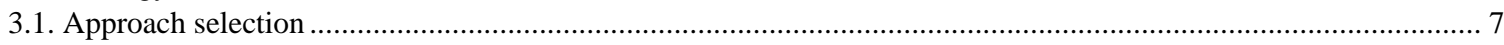

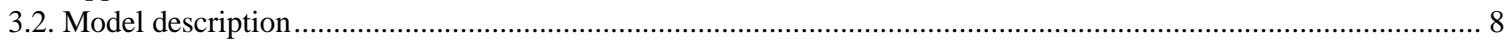

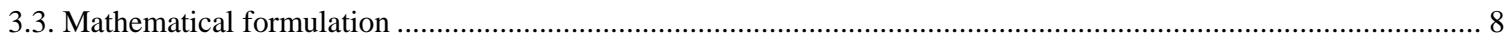

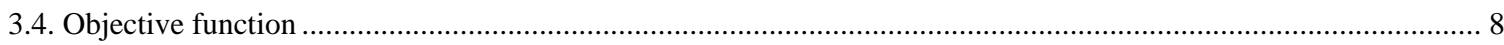

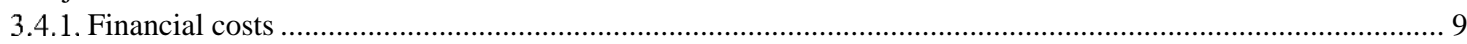

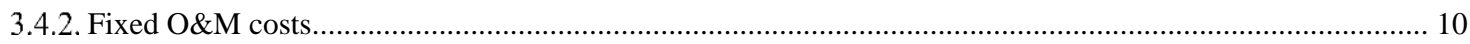

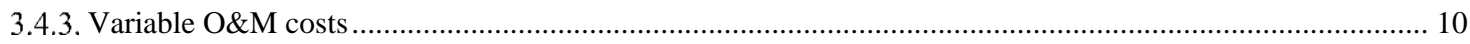

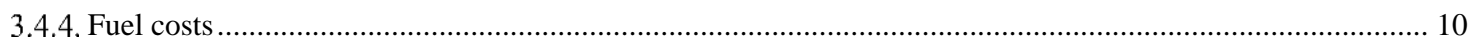

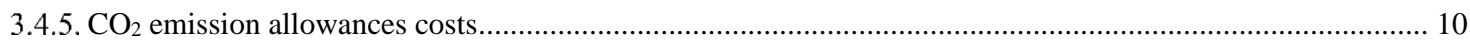

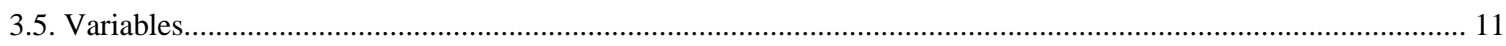

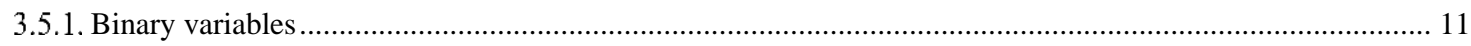

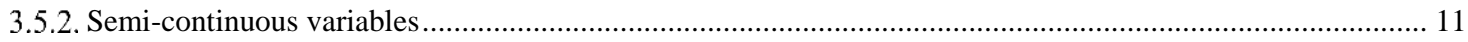

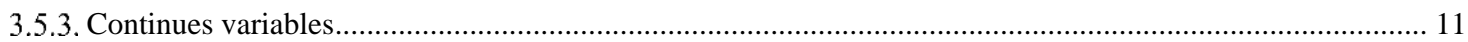

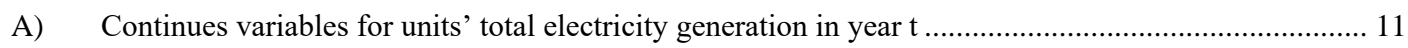

B) Continues variables for RES' installed power............................................................................... 11

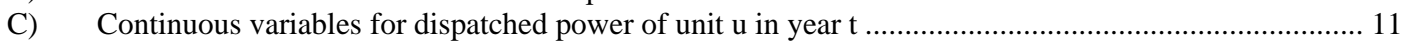

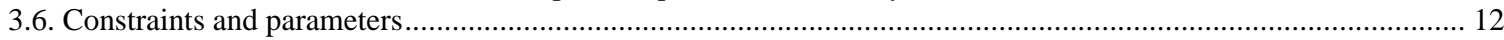

3.6.1. Long-term generation expansion planning...................................................................................... 12

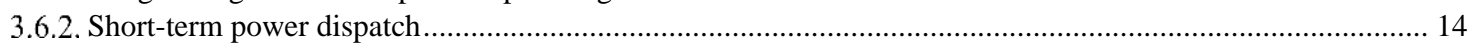

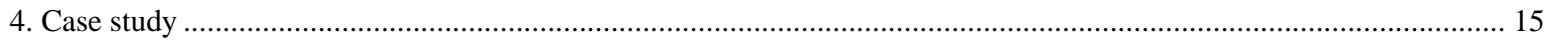

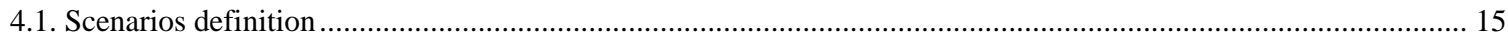

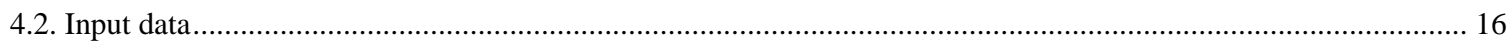

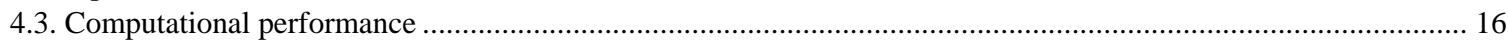

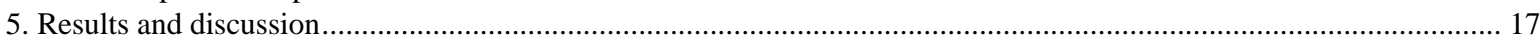

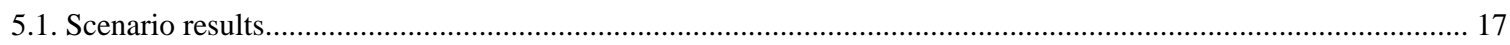

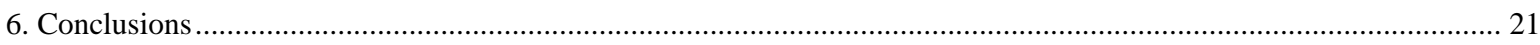

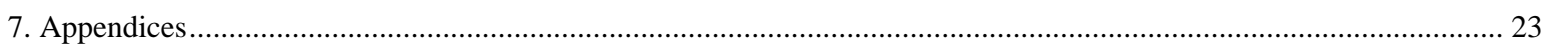

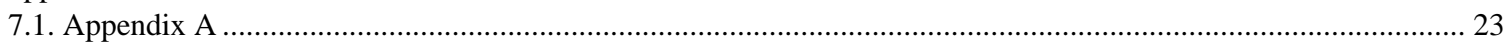

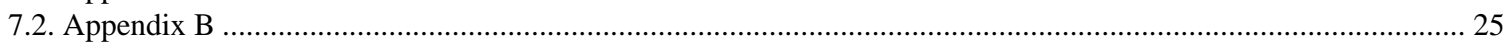

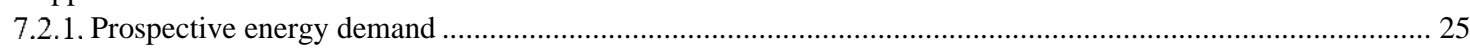

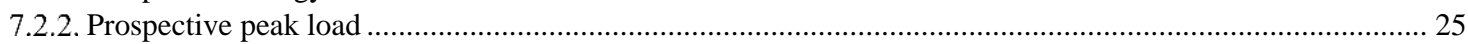

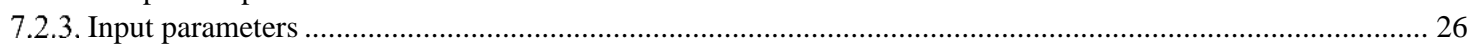

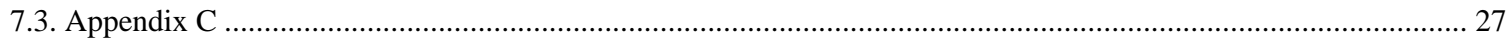

\section{Introduction}

\subsection{Research motivation}

Energy mix (EM) is a technological structure of electricity generating units in a power system, able to provide power and energy balance. It is mainly determined by the total costs of the electricity generation, but also by technical and economic constraints or political decisions.

Although in most cases, generating units are constructed by private investors, the energy mix planning, as a strategic task, is entrusted to the policy makers and government administration. They possess administrative and legal instruments for controlling EM development. Adequate EM requires a long-term planning and it cannot be frequently modified because of the inertia in the power system investments.

Traditionally, EM optimization, known also as generation expansion planning (GEP), has aimed at reducing cost of electricity production taking into account an access to the fuel and technical constraints on the power 
system operation. Increasing environmental concerns lead to the strict energy and climate policies, which are the main stimuli to EM. In October 2014, the European Council agreed to $43 \%$ reduction of $\mathrm{CO}_{2}$ emissions for the period between 2020 and 2030 with the reference to year 2005.

The estimation of the future EM has to take into account the security of electricity supply and power system reliability. The obtained set of power generating units has to meet not only the peak power demand but also fulfil the requirements of the safe operation of the power system in every moment. Thereby, the short-term variability of generation caused by the intermittent RES (wind turbines and PV installations) and daily fluctuations of load requires the backup capacity that will be flexible enough to balance these changes. This requirement is not fully included in existing EM optimization models.

The paper presents the development of useful and reliable methodology for EM optimization taking into account different approach to power generating units, costs and power system reserves. It demonstrates that it is possible to develop bottom-up and long-term model for energy mix optimization, based on representation of individual generation units with annual costs calculation (including financial ones) and daily requirements of power system operation (such as daily, not only annual, power reserve margin). Despite the complexity of the problem, an adequate modelling allows for preserving computational efficiency of the model [1].

Novel EM optimization method is examined using Polish power sector data. It presents the possible Polish energy mix that would be in accordance with the EU energy policy and provide the sustainable power system development. The model was used by the Polish Ministry of Economy for the preparation of the Energy Policy for Poland until 2050, and was used for analyses made by the National Development Council and presented to the President of the Republic of Poland, describing situation of the power sector in Poland.

\subsection{Key contribution}

The contribution of research presented is a novel concept of energy mix optimization, which better than existing models reflects reality of the power system and energy sector operation. The presented generation expansion planning tool is based on the MILP and incorporates every single centrally dispatched power generating unit. The required daily power reserves (primary, secondary and tertiary) of individual power units are included in the model, what allows for RES development linked with conventional thermal power plants. Moreover, the model optimizes both: power capacities to cover power balance and electricity generation to cover energy balance within two separated sets of variables. Thus, the model takes into account the limited operation of conventional units that is caused by the overcapacity and the presence of prioritized RES in the power dispatch. This phenomenon increases the overall unit's cost since it does not fully benefit from its availability. It allows considering the impact of decrease of operation time of conventional units on the rise of overall units' costs in the long perspective. Additionally, the costs in the model are calculated annually what allows for the better reflection of the power units' construction costs (including financial costs) and operation costs.

\subsection{Paper structure}

At the beginning of the paper there is an introduction with key contribution of the novel energy mix optimization model. Subsequently, there are presented recent achievements in Energy System Modeling with thorough review of already existing EM optimization models. Next, the authors presented methodology description with explanation of the need of binary programing in energy mix optimization, model structure and complete description of mathematical formulations in the model. Quality of the model is examined in the next section and results are presented. In the end, after conclusions, there are appendices that help to order the data and understand some of the assumptions made in the article. 


\section{Recent Achievements in Energy System Modelling}

Energy Mix (EM) optimization, called also Generation Expansion Planning (GEP), is a part of wide field of research, named energy system modeling. There are two main approaches for energy system modeling: topdown and bottom-up. The former focuses on the economic issues of the energy system operation, while the latter represents engineering approach and starts from technical aspects and procedures [2]-[4]. There are several comprehensive and extensive reviews of the energy system modeling. Connolly et al. in [5] created clear unification of the developed models according to the tools applied (simulation, scenario, equilibrium, top-down, bottom-up, operation optimization, investment optimization and combined tools). The more tools are used, the more model is complicated, but on the other hand provides more general solutions. Review mentioned and other [3], [6], [7] allow for better evaluation of the novel models proposed.

Sometimes the top-down models are identified shortly as energy system models, while bottom-up as power system ones. Combining them is always complex but highly required process. According to the [8] and [9], the need for the soft links between power system models and energy system models are needed due to the appearing gaps between engineering and economic approaches. Until now, there have been many optimization models developed, but according to the authors' best knowledge, none of them allows for long-term GEP optimization taking into account daily requirements of power system operation (primary, secondary and tertiary reserve) and their relation to RES penetration:

Table 1. Characteristics of existing models - part 1

\begin{tabular}{lll}
\hline Model & Characteristics & Remarks \\
\hline$[8],[9]$ & PLEXOS & - One of the most important, commercially available product \\
& - Deterministic, power system MILP model & - Does not include fixed operation and maintenance cost (FOM) \\
& - Unit commitment and dispatch model extended to & - Does not embody all aspects of long-term energy mix planning \\
& longer horizon (calculation with hourly time step). & (loans, project finance, debt, equity etc.)
\end{tabular}

As a general rule, EM optimization is a dynamic problem. Therefore, it should apply the dynamic programming (DP). However, due to the complexity, such an approach is limited to small, usually, benchmark systems, in a short-term analysis [12]-[15], thus they are not applicable. Complexity increases massively extending the model size, what is knows in the literature as "curse of dimensionality" [16].

Some researches focused on nonlinearity in optimization models. There were attempts to apply MINLP (Mixed Integer Nonlinear Programming) for energy mix, but pure nonlinear approaches to the GEP can be also found in literature. The commonly used approach to the MINLP is application of the Benders decomposition [19], [20]. It allows for transformation of the typical MINLP problem into mixed integer linear programming problem (MILP). This method ensures computational efficiency and guarantees a global solution (while the pure MINLP provides with only local ones). 
Table 2. Characteristics of existing models - part 2

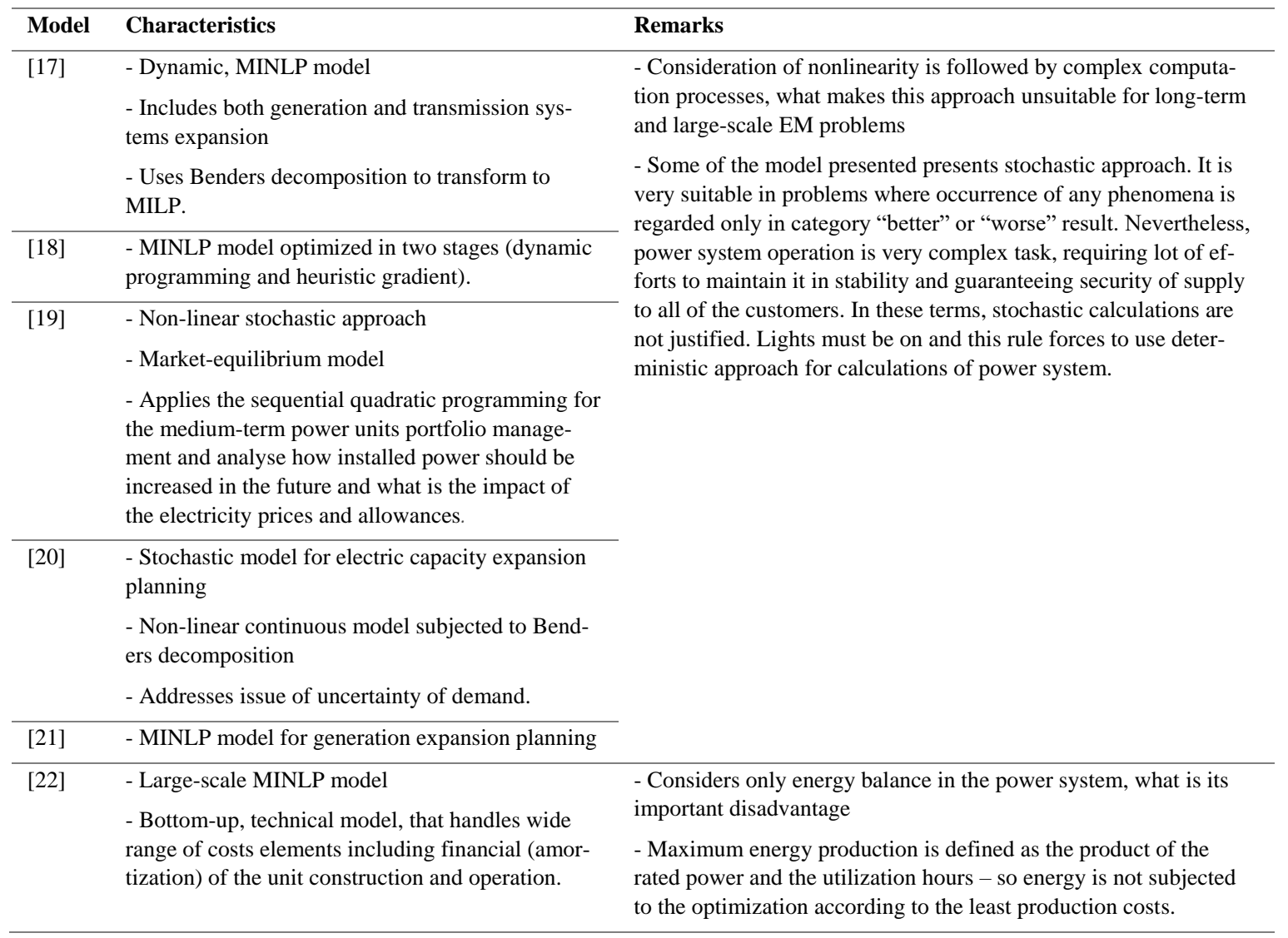

Because the MINLP models are often transformed to the MILP problems to facilitate model solving and to guarantee the local solution, some researchers have started to develop pure MILP model without the need for Benders decomposition application. First MILP models were based on the decision tree method [23]. Nowadays, decision tree is a basis for advanced MILP solvers:

Table 3. Characteristics of existing models - part 3

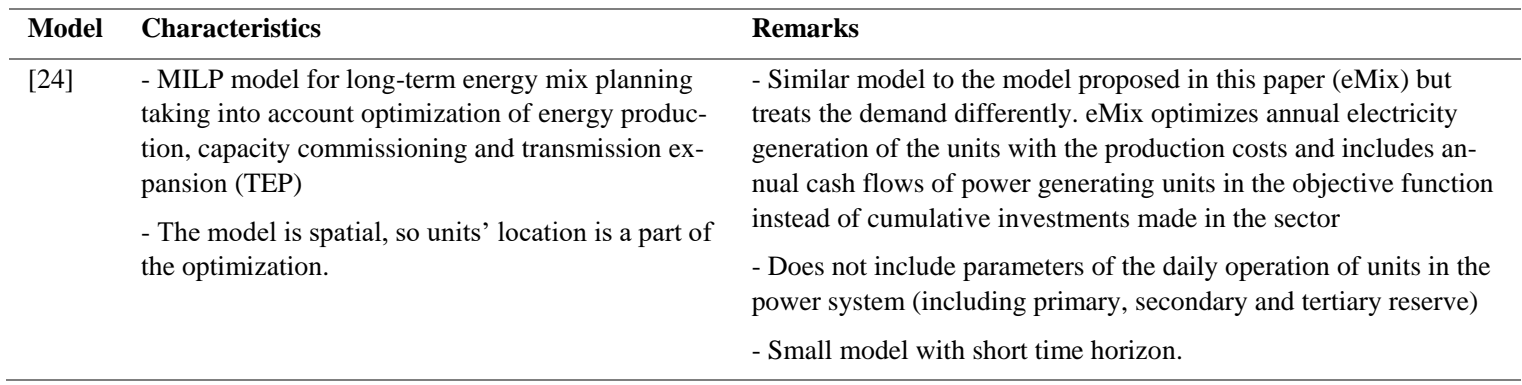

Another group of the MILP energy mix optimization models focus on the uncertainty of the input data and model parameters:

Table 4. Characteristics of existing models - part 4

\begin{tabular}{lll}
\hline Model & Characteristics & Remarks \\
\hline$[25]$ & - Includes financial risk management & - Not a deterministic model \\
& - Two stage stochastic model for EM optimization & - Does not include short-term power system requirements \\
\hline
\end{tabular}




\begin{tabular}{|c|c|c|}
\hline [26] & $\begin{array}{l}\text { - Stochastic MILP model } \\
\text { - Objective function combines together costs of } \\
\text { power units' life cycle and environmental impact. }\end{array}$ & $\begin{array}{l}\text { - The model does not provide optimization of energy production, } \\
\text { which in this case is an effect of availability factor of units con- } \\
\text { structed. }\end{array}$ \\
\hline [27] & $\begin{array}{l}\text { - MILP model for generation and transmission ex- } \\
\text { pansion planning } \\
\text { - Focuses on the reliability aspect of the power sys- } \\
\text { tem operation and apply probabilistic model of the } \\
\text { generators and line outages. }\end{array}$ & $\begin{array}{l}\text { - Only power output for the units is considered } \\
\text { - The paper provides linearization of the nonlinear costs functions } \\
\text { but costs elements considered are simplified (only overnight costs } \\
\text { and generally named operation costs are included). }\end{array}$ \\
\hline [28] & $\begin{array}{l}\text { - Mixed integer fractional energy system planning } \\
\text { - Solves the problem of multi criteria optimization } \\
\text { under unknown model parameters. }\end{array}$ & $\begin{array}{l}\text { - Using fractional programming brings interesting results to the } \\
\text { long-term optimization of energy systems. It allows considering } \\
\text { different criteria in the optimization, that cannot be expressed } \\
\text { within the costs parameters. However, such an approach is very } \\
\text { complex, what hinders to understand the results, what is especially } \\
\text { important for the power system calculation ("lights must be on"). } \\
\text { Model also does not address the issue of power system reserves. }\end{array}$ \\
\hline
\end{tabular}

Model simplification based on the neglecting the individual power units' representation and using only technologies instead is a common approach to the energy mix optimization. It does not allow for considering units' particular features and parameters including financial ones. Therefore, the GEP based on linear programming is limited in use for realistic problems [6].

Table 5. Characteristics of existing models - part 5

\begin{tabular}{|c|c|c|}
\hline Model & Characteristics & Remarks \\
\hline [29] & - Linear generation expansion planning model & \multirow{4}{*}{$\begin{array}{l}\text { - It does not allow for considering units' particular features and pa- } \\
\text { rameters including financial ones. Therefore, the GEP based on } \\
\text { linear programming is limited in use for realistic problems [6]. } \\
\text { - Both models for China represent only overnight costs. }\end{array}$} \\
\hline [30] & $\begin{array}{l}\text { - Multiregional linear EM model for China without } \\
\text { energy production optimization }\end{array}$ & \\
\hline [31] & $\begin{array}{l}\text { - Long-term, linear model with wide representation } \\
\text { of zero emission sector in order to analyse carbon } \\
\text { dioxide mitigation for China }\end{array}$ & \\
\hline$[32]$ & $\begin{array}{l}\text { - The linear model for energy mix optimization } \\
\text { named "Optimal energy mix for Poland until } \\
\text { 2060", prepared by the Chancellery of the Prime } \\
\text { Minister of the Republic of Poland. }\end{array}$ & \\
\hline
\end{tabular}

A flexibility of power generating units is another, but very important feature that should be incorporated in the energy system models. It is crucial for sustainable policy analysis, when large amount of RES are entering the mix. Therefore, planning the energy mix should consider the need of back up units for RES and units flexibility to mitigate the quick changes in generation of RES. Some further researches can be found in [8], [11], [33].

Table 6. Characteristics of existing models - part 6

\begin{tabular}{|c|c|c|}
\hline Model & Characteristics & Remarks \\
\hline$[34]$ & $\begin{array}{l}\text { - Flexibility need caused by the wind generation is } \\
\text { analysed taking into account demand response. }\end{array}$ & $\begin{array}{l}\text { - The model includes flexibility through elasticity assumptions } \\
\text { (own-price and cross-price elasticities) which is a rough approxi- } \\
\text { mation and is not applicable for power system operation optimiza- } \\
\text { tion }\end{array}$ \\
\hline$[35]$ & $\begin{array}{l}\text { - Deals with planning of optimal expansion of fast- } \\
\text { responding generating capacity. The objective is to } \\
\text { accommodate the uncertainty of wind generation, } \\
\text { but only on the basis of daily dispatch (MILP } \\
\text { model), not long-term planning } \\
\text { - Addresses a need for considering flexibility issue } \\
\text { in the energy mix optimization } \\
\text { - Includes daily load curve, which is a basis for } \\
\text { flexibility analyses for the defined set of power }\end{array}$ & $\begin{array}{l}\text { - Such approach was not applied yet in other GEP models, accord- } \\
\text { ing to the authors' best knowledge. However, model considers } \\
\text { only single year on the basis of Unit Commitment and Dispatch. }\end{array}$ \\
\hline
\end{tabular}


The mathematical tool that helps to incorporate the uncertainty and flexibility issues is fuzzy optimization. The papers over this topic can be find in [36]-[38]. Models combining the fuzzy logic although linear, lead to a serious problem related to the solvers that are never designed for fuzzy linear programing.

So far, energy in the power system has been flowing in the "top-down" structure - from large generating units to the customers. But it is going to change in the near future with the development of prosumers and Distributed Generation (DG). Therefore, this issue should be also considered in the EM optimization models. The problem of sizing and locating the DGs in the power system (distribution network) for meeting the voltage stability requirements and power losses reduction can be found in [39], [40]. Different problem of the distribution network expansion planning with the improvement of reliability index is solved in [41]. These are supporting information about state of the art in EM optimization, as in the $e M i x$ fuzzy optimization as well as uncertainty and DG related issues are not managed.

Our model provides a bottom-up optimization approach that puts an emphasis on the technical parameters of individual units and power system as a whole. It also incorporates the changes in the power dispatch that are caused by the RES expansion. On the other side it has a well-developed microeconomic side and includes financial cost that are calculated annually. There are other models that individually include some of the parameters of $e$ Mix, but according to the authors' best knowledge, this is the first model that includes all of those parameters in the single optimization process.

\section{Methodology}

\subsection{Approach selection}

The purpose of the research presented in the article was to create the tool for an energy mix optimization in time horizon defined, with possibly the most precise representation of the technical aspects of power system and individual units operation. Therefore, a bottom-up optimization framework was selected. According to the research objective, authors rejected market equilibrium approach. It is often used, where the research problem concerns the impact of the development of power sector on the economy of the country or region. Those models describe the demand and supply side through the mathematical formulas representing the relations between the sectors on the basis of factors selected e.g. capital, labor, leisure time, production components within the utility and production function. The whole computational process is based on the flow of goods between actors and sectors. However, in equilibrium models, it is not possible to define very detailed technical parameters of any sector operation such as parameters of the individual producers (in our case the parameters of the power generating units).

Selecting bottom-up optimization framework entails the need for decision how the problem will be defined as dynamic/static or linear/nonlinear problem. The dynamic programming was rejected because of the curse of dimensionality problem - it is not possible to create an efficient, large-scale model based on dynamic programming. Nonlinear programming was not applied because of their negative influence on computational process there is no guarantee that the model's outcome is globally optimal. Furthermore, it lengthens the computational time and depends on the starting point. For the described problems relating to the large scale optimization, the linear programming seems to be the best solution. Linear, constrained optimization is always computationally effective and guarantees the global solution. Apart from that, linear solvers are very efficient nowadays. Taking into account the advantages of the linear approach, and needs for the research question, modification of pure 
LP has been selected - MILP. The MILP is additionally necessary for further development of the methodology used for generation expansion planning.

\subsection{Model description}

eMix is the bottom-up optimization tool developed for the long-term generation expansion planning but also considering short-term requirements of the power system. The calculations are carried out to 2050 with annual time step. The objective function of this optimization includes all the construction and operation costs. Since all the costs are calculated annually, the investment cost is included together with the financial cost in the annual installment instead of an overall cost burden in the construction period (see 3.4.1).

The presented model incorporates the required $18 \%$ of the power reserve in relation to average yearly demand as well as short-term primary, secondary and tertiary reserves to balance the fluctuations of daily load and intermittent generation. The short-term reserve requirements are calculated for the one day in each year that represents the worst-case scenario (high demand followed by low generation). The number of representative days for which reserves are considered can be easily extended.

The model developed is fully adjustable and enables selection of different timeframes (optimization horizon) from single year up to 50; and time steps - from single hour to single years or other defined periods.

eMix is driven by exogenously defined power and energy balance and constraints. It includes the upper constraint for generation technologies (technical potential) and primary fuels' limits. The model involves large power units: (a) lignite 450MW and 900MW, (b) hard coal $450 \mathrm{MW}$ and 900MW, (c) gas 450MW, (d) biomass 100MW and 200MW, (e) nuclear 1000MW and 1600MW, (e) hydro CDGUs; renewable energy sources: (a) hydro non-Centrally Dispatched Generating Units (nCDGUs), (b) PV, (c) biomass nCDGUs, (d) biogas, (e) wind onshore, (f) wind offshore; and other nCDGUs: (a) gas-fired combined heat and power units (CHPs), (b) coal-fired CHPs, (c) industrial units. The model incorporates RES development, yet the minimum share of RES is implemented in the model as a constraint, e.g. to be coherent with European Energy Policy.

\subsection{Mathematical formulation}

The mathematical formulation in $e$ Mix requires the specification of set $U$ that stands for generating units $u$ and set $T$ that stands for time horizon 2020-2050 with annual step $t$. Indices $u$ ', $u$ ' ' and $u$ ', share the set $U$ where $U^{\prime}, U^{\prime \prime}$ and $U^{\prime \prime}$ ' are subsets of set $U$ - formula (1). Set $U^{\prime}$ denotes Centrally Dispatched Generating Units (lignite, hard coal, gas, biomass and nuclear), set $U$ ', stands for hydro CDGUs, set $U$ ', represents renewable energy sources: small hydro units (with rated power below 100MW), biomass and biogas units and intermitted RES (wind on- and offshore, PV). Such division comes from the way of modelling of particular units (see 3.5).

$$
U^{\prime}, U^{\prime \prime}, U^{\prime \prime \prime} \subset U
$$

CDGUs are modelled using MILP while nCDGUs are taken into account in terms of technology using linear programming. According to authors best knowledge, the LP is sufficient for the nCDGUs modelling, because their development is not subjected to central planning activity.

Detailed description of units in Appendix A.

\subsection{Objective function}

The objective function (2) represents the total costs of power generating units' construction and operation in long-term horizon. The costs are divided into fixed costs $C F_{u, t}$ and variable costs $C V_{u, t}$. The costs $C_{-} D I S P_{u, t}$ are the variable costs of power dispatch for peak hour in each year $t$. Symbol $P_{-} I_{u, t}$ is the installed power and $E_{u, t}$ is the annual electricity generation of unit $u$ in year $t$. The symbol $P_{-} D I S P_{u, t}$ represents the dispatched power of unit $u$ in representative peak hour in year $t$. 
The fixed and variable costs (first and second element of objective function) represent the typical approach for energy mix optimization with distinguished optimization of power capacity and energy generation. The third component introduces the novel approach, which combines the long-term planning with short-term operation of power units. The role of the statement $P_{-} D I S P_{u, t} C_{-} D I S P_{u, t}$ is to sort all commissioned units in year $t$ taking into account their variable costs (approximation of the economic dispatch in a power system). In a consequence, the units are ordered from the least to the most expensive preserving their technical parameters. Units with the lowest variable costs are dispatched in representative peak hour. Such an approach enables the introduction of the evaluation of power systems reserves.

$$
\sum_{u \in U}\left(\sum_{t \in T}\left(P_{-} I_{u, t} \cdot C F_{u, t}+E_{u, t} \cdot C V_{u, t}+P_{-} D I S P_{u, t} \cdot C_{-} D I S P_{u, t}\right)\right)
$$

Adding the costs of the commitment and dispatch for single hour to the objective function is an artificial modification. The objective function still represents the costs and the modification applied can be considered as transformation of three dimensional problem (cost of capacity, cost of annual generation, costs of hourly operation) to the one dimension problem, which value can be calculated, compared and subjected to minimization. It was precisely investigated by the authors, that additional element in an objective function before posing constraints on dispatch do not affect long-term planning.

The formula (3) is used to calculate the fixed costs $C F_{u, t}$, which consist of financial costs of debt and equity $C F I N_{u, t}$ and fixed operation and maintenance costs (FOM) COMFIX $X_{u, t}$. The variable costs $C V_{u, t}$, presented in formula (4), include variable operation and maintenance costs (VOM) COMVAR $R_{u, t}$, fuel costs $C F U E L_{u, t}$ and $\mathrm{CO}_{2}$ emission allowances costs $C E M C O 2_{u, t}$.

$$
\begin{gathered}
\forall u \in U, \forall t \in T \quad C F_{u, t}=\text { CFIN }_{u, t}+\text { COMFIX } \\
u u, t \\
\forall u \in U, \forall t \in T \quad C V_{u, t}=C O M V A R_{u, t}+C F U E L_{u, t}+C E M C O 2_{u, t}
\end{gathered}
$$

All costs are expressed in euro per unit: fixed costs per $M W$, variable costs per $M W h$, while variable cost of power dispatch per $M W \_h$.

\subsubsection{Financial costs}

One of the important features of the presented model, which is not fully included in other tools, is the implementation of financial costs $C F I N_{u, t}$, which are repaid annually. It is assumed that every power generating unit $u$, being constructed and connected to the power system in year $t$, is not being paid by its private equity only. In the market environment investments rarely are covered by private equity, therefore, additional capital (leverage) is required. The large investment can be handled according to the project finance or corporate financing scheme. In $e$ Mix, project finance is selected. Every investment requires bank loan and in order to reflect bank interest rate and cost of private capital, Weighted Average Cost of Capital (WACC) is calculated on the basis of assumed leverage and investor equity (Table 19 in Appendix B).

The construction costs of power unit $u C_{C O N}$, presented in formula (5), contain two elements, which denote investors debt: overnight costs $C O V_{u}$ and interest $I N T_{-} C O N_{u}$ accrued during construction time $C T_{u}$. The interest (6) depends on factor $K_{-} A E X P_{u, t}$, which represents the percent of annual expenditures in construction time according to construction stages of the investment. It varies in terms of power units' technology (Table 18 in Appendix B). The index $c$ stands for single year in construction time $C T_{u}$, while the $i$ is a supplementary index.

$$
\forall u \in U \quad \text { CCON }_{u}=\operatorname{COV}_{u}+I_{N} T_{-} C_{u}
$$

$$
\begin{gathered}
\forall u \in U \quad I N T_{-} C O N_{u}=\sum_{c \in\left[1, C T_{u}\right]}\left(\sum_{i \in[1, c]}\left(K_{-} A E X P_{u, i}\right) \cdot C O V_{u} \cdot W A C C\right) \\
\text { where } \sum_{c \in\left[1, C T_{u}\right]} K_{-} A E X P_{u, c}=100 \%
\end{gathered}
$$


Also, the loan repayment includes the interest. In presented model, the decreasing loan repayment rate is assumed, which means that during repayment time the investor repays the fixed instalment $I N S_{u}$ with diminishing interest $I N T_{-} R T_{u, t}$. Therefore, the annual repayment of financial cost of the unit construction $C F I N_{u, t}$ consists of this two elements (7). The repayment period $R T_{u}$ is assumed individually for each unit $u$. It cannot be longer than units lifetime $L T_{u}$. This approach presents realistic cost of power unit construction with debt repayment and capital interest.

$$
\forall u \in U, \forall t \in T \quad C F I N_{u, t}=I N S_{u}+I N T_{-} R T_{u, t}
$$

Formulas (8) and (9) presents the fixed installment and decreasing interest, respectively. The index $r$ represents one year in repayment period $R T_{u}$.

$$
\begin{gathered}
\forall u \in U \quad I N S_{u}=\operatorname{CCON}_{u} / R T_{u} \\
\forall u \in U, \forall r \in\left[1, R T_{u}\right] \quad I N T_{-} R T_{u, r}=\left(\operatorname{CCON}_{u}-(r-1) \cdot I N S_{u, r}\right) \cdot W A C C
\end{gathered}
$$

\subsubsection{Fixed $O \& M$ costs}

The FOM costs COMFIX $X_{u, t}$ are the power generating unit's $u$ expense that does not depend on electricity generation. This type of costs includes: (a) structures and grounds maintenance, (b) administrative costs, (c) maintenance costs which does not require a long-term unit shutdown, e.g. maintenance of water circuits, feed pumps[42], [43], [44]. The FOM are presented in Table 18 in Appendix B depending on technology.

\subsubsection{Variable $O \& M$ costs}

The VOM costs $C O M V A R_{u, t}$ depend on energy generation. They consist of (a) major maintenance cost, (b) waste expenses, (c) lubricants, etc. Their value mostly depends on the repair of plant's elements [42], [43], [44]. The Table 18 in Appendix B presents the VOM depending on technology.

\subsubsection{Fuel costs}

The different fuel costs $C F U E L_{u, t}$ can be assigned for each power unit $u$ and time period $t$. This formulation enables the inclusion of different contracts between power stations and mines, and fuel price. The formula (10) depicts fuel costs for each unit $u$ in year $t$ as the product of fuel consumption (it depends on the plant's gross efficiency $\eta_{u}$ ) and price for primary fuel $P F U E L_{u, t}$. The factor $K_{-} G J M W h$ transforms $G J$ to $M W h$. The values of efficiency and primary fuel parameters can be found in Table 16 and Table 17 in Appendix B, respectively.

$$
\forall u \in U, \forall t \in T \quad C F U E L_{u, t}=\frac{1}{\eta_{u}} \cdot K_{-} G J M W h \cdot P F U E L_{u, t}
$$

\subsection{5. $\mathrm{CO}_{2}$ emission allowances costs}

According to European Energy Policy and European Union Emissions Trading System (EU ETS) the power generating units have to buy allowances for $\mathrm{CO}_{2}$ emissions. In presented model price for certificates $\mathrm{CCO}_{t}$ is assumed for each year and is a part of scenario simulated. The $\mathrm{CO}_{2}$ emission's costs $C E M C O 2_{u, t}$, presented in (11), are the product of price $C C O 2_{t}$ and emission's intensity $E M I S S_{u, t}$ of unit $u$ in year $t$.

$$
\forall u \in U, \forall t \in T \quad \operatorname{CEMCO2}_{u, t}=\operatorname{EMISS}_{u, t} \cdot \mathrm{CCO}_{t}
$$

Emission's intensity of power plant is calculated as the quotient of the primary fuel's emission EMISS_PRIM$F U E L_{u, t}$ and units' efficiency $\eta_{u}(12)$. Both parameters are presented in Table 16 and Table 17 in Appendix B.

$$
\forall u \in U, \forall t \in T \quad E M I S S_{u, t}=E M I S S_{-} P R I M F U E L_{u, t} / \eta_{u}
$$




\subsection{Variables}

\subsubsection{Binary variables}

In $e$ Mix, the role of binary variables is: (a) to express the units' presence in the energy mix in year $t$ - variables $X_{u}$ and (b) to represent the units' commitment to operation in representative peak hour in each year $t$-variables $X_{-} D I S P_{u}$.

The authors have developed the novel binary variables formulation, which allows for the computationally efficient power units representation in MILP energy mix optimization. The starting point was a well-known methodology used in unit commitment. The authors analyzed the methods presented in [45]-[51] and adapted them to long-term energy mix planning. The detailed analysis of this methodology, with presentation of computational parameters, is included in [1]. Formulas (13) and (14) present the relation between variables $X_{u}$, and $X_{-} D I S P_{u}$. They stand for the possibility of commitment of unit $u$ ' to the power dispatch only when it already exists in the energy mix.

$$
\begin{gathered}
\forall u^{\prime} \in U^{\prime} \quad X_{u^{\prime}}=0 \Rightarrow X_{-} D I S P_{u^{\prime}}=0 \\
\forall u^{\prime} \in U^{\prime} \quad X_{u^{\prime}}=1 \Longrightarrow X_{-} D I S P_{u^{\prime}}=0 \text { or } X_{-} D I S P_{u^{\prime}}=1
\end{gathered}
$$

\subsubsection{Semi-continuous variables}

The semi-continuous variables can take the value " 0 " or the value between defined lower and upper bound. In eMix, those variables are used in modelling the hydro CDGUs. Generally, large hydro units represent the rated power above $100 \mathrm{MW}$ but there is no typical value assigned to this technology. Hence, in presented model the rated power is expressed by semi-continues variables $P_{-} I+H Y D C D G U_{u^{\prime \prime}, t}$.

This type of variables includes both information about unit's $u$ ' existence in the energy mix and information about value of power, which in $e$ Mix varies from $100 \mathrm{MW}$ to $200 \mathrm{MW}$.

\subsubsection{Continues variables}

The role of continues variables is to represent: a) the total electricity generation of unit $u$ in year $\left.t-E_{u, t}, \mathrm{~b}\right)$ the installed power of RES, which are modelled linearly $\left.-P_{-} I-R E S_{u}{ }^{\prime \prime}, t, \mathrm{c}\right)$ the dispatched power of unit $u$ in representative peak hour in year $t-P_{-} D I S P_{u, t}$.

A) Continues variables for units' total electricity generation in year $t$

The total electricity generation of power unit $u$ in year $t$ is modelled via continues variables $E_{u, t}$. The formulas (15)-(16) present the relation between $E_{u, t}$ and installed power $P_{-} I_{u, t}$. The electricity generation is possible only if unit $u$ is constructed and can operate in year $t$.

$$
\begin{array}{ll}
\forall u \in U, t \in T & P_{-} I_{u, t}=0 \Rightarrow E_{u, t}=0 \\
\forall u \in U, t \in T & P_{-} I_{u, t}>0 \Rightarrow E_{u, t}>0
\end{array}
$$

B) Continues variables for RES' installed power

The installed power of small renewable energy sources (with rated power below $100 \mathrm{MW}$ - i.e. small hydro, biomass, biogas, wind on- and offshore and PV units), is modelled linearly using continues variables $P \_I \_R E S_{u^{\prime \prime}, t}$. In consequence, the units are considered as a value of capacity constructed in particular year $t$. The relation between power and electricity generation of RES is the same as in formulas (15)-(16).

C) Continuous variables for dispatched power of unit $u$ in year $t$

In terms of daily power dispatch, the continues variables represent the dispatched power of CDGU $u$ ' in representative peak hour in year $t$. The formulas (17) and (18) present the relation between binary variables $X \_D I S P_{u}$ 
(which stands for unit commitment) and dispatched power for CDGUs. For other types of units, i.e. RES and other nCDGUs, the dispatched power is implemented as a maximum available power, because in short-term operation of the power system they are must-run units (CHPs operate according to the heat demand, and RES according to wind or solar conditions). Hence, there is no need of additional variables for their representation in daily dispatch and, in consequence, they are represented via parameters.

$$
\begin{array}{ll}
\forall u^{\prime} \in U^{\prime}, t \in T & X_{-} D I S P_{u^{\prime}}=0 \Rightarrow P_{-} D I S P_{u^{\prime}, t}=0 \\
\forall u^{\prime} \in U^{\prime}, t \in T & X_{-} D I S P_{u^{\prime}}=1 \Rightarrow P_{-} D I S P_{u^{\prime}, t}>0
\end{array}
$$

\subsection{Constraints and parameters}

The presented model is driven by constraints and parameters, which contain technical, economic, environmental and political aspects of power system operation. These issues are divided into two main parts: (a) long-term generation expansion planning and (b) short-term power dispatch.

\subsubsection{Long-term generation expansion planning}

In long-term perspective (2020-2050) the crucial parameters, which determine the operation of the power system are: power installed and annual electricity generation. These aspects have to be complemented by local or international targets, which express the environmental or political requirements, e.g. $\mathrm{CO}_{2}$ emissions limits or RES share.

In $e$ Mix, the total installed power in the system in year $t-P_{-} I_{-} T O T A L_{t}$ consists of installed power of conventional CDGUs - P_I_CDGU $u_{u^{\prime}, t}$ (lignite, hard coal, gas, biomass, nuclear units), hydro CDGUs $P \_I \_H Y D C D G U_{u}{ }^{\prime \prime}, t$, renewable energy sources $-P \_I \_R E S_{u}{ }^{\prime \prime}, t$, (small hydro, biomass, biogas, wind on- and offshore, PV units) and other nCDGUs - P_I_NCDGU $U_{t}$. The formulas (19) and (20) present all the components. All the units are divided into two categories: a) the existing units, which were commissioned before the year 2020 (when the optimization starts), and b) the new units, which are being constructed from 2020 to 2050 (during the optimization process). The capacity of existing units is presented in Table 15 in Appendix B.

$$
\begin{gathered}
\forall t \in T \sum_{u \in U} P_{-} I_{u, t}=\sum_{u^{\prime} \in U^{\prime}} P_{-} I_{-} C D G U_{u^{\prime}, t}+\sum_{u^{\prime \prime} \in U^{\prime \prime}} P_{-} I_{-} H Y D C D G U_{u^{\prime \prime}, t}+\sum_{u^{\prime \prime \prime} \in U^{\prime \prime \prime}} P_{-} I_{-} R E S_{u^{\prime \prime \prime}, t} \\
\forall t \in T \quad P_{-} I_{-} T O T A L_{t}=\sum_{u \in U} P_{-} I_{u, t}+P_{-} I_{-} N C D G U_{t}
\end{gathered}
$$

The power of nCDGUs is divided into CHPs and industrial units. These units are self-dispatched (heat driven, industrial process driven or natural resources driven electricity generation).

The requirement for the value of power (power balance) is related to the power, which can be disposed by TSO, i.e. available power $P_{-} A_{u, t}$ To obtain the available power, according to formula (21), the installed power is multiplied by the power availability factor $K_{-} P A_{u, t}$. Similarly, the available power for nCDGUs is presented in (22).

$$
\begin{gathered}
\forall u \in U, t \in T \quad P_{-} A_{u, t}=K_{-} P A_{u, t} \cdot P_{-} I_{u, t} \\
\forall t \in T \quad P_{-} A_{-} N C D G U_{t}=K_{-} P A_{-} N C D G U_{t} \cdot P_{-} I_{-} N C D G U_{t}
\end{gathered}
$$

Finally, the power balance is presented in (23). In each year $t$, the total available power in the system must cover the prospective peak load $P_{-} D_{t}$ with required margin, which is expressed by percentile factor $K_{-} P R E S E R V E_{t}$.

$$
\forall t \in T \quad \sum_{u \in U} P_{-} A_{u, t}+P_{-} A_{-} N C D G U_{t} \geq P_{-} D_{t}+K_{-} P R E S E R V E_{t} \cdot P_{-} D_{t}
$$

The total electricity generation in the whole system in each year $t$ includes: (a) electricity generation of CDGUs and RES (what is presented in (24)) and (b) the electricity produced by nCDGUs (CHPs and industrial). As a 
consequence, the constraint for energy balance, presented in formula (25), means that the total electricity generation in each year $t$ must be equal to prospective, annual energy consumption in the system $E_{-} D_{t}$.

$$
\begin{gathered}
\forall t \in T \quad \sum_{u \in U} E_{u, t}=\sum_{u^{\prime} \in U^{\prime}} E_{-} C D G U_{u^{\prime}, t}+\sum_{u^{\prime \prime} \in U^{\prime \prime}} E_{-} H Y D C D G U_{u^{\prime \prime}, t}+\sum_{u^{\prime \prime \prime} \in U^{\prime \prime \prime}} E_{-} R E S_{u^{\prime \prime \prime}, t} \\
\forall t \in T \sum_{u \in U} E_{u, t}+E_{-} N C D G U_{t}=E_{-} D_{t}
\end{gathered}
$$

The possible electricity generation of unit $u$ is limited to minimum and maximum levels (equations (26) and (27)). The former equation specifies that unit $u$ can produce the volume of energy that is lower or equal to the product of availability factor $K \_A_{u, t}$, installed power $P_{-} I_{u, t}$ and the hours in a year $Y-8760 h$. The availability factor includes the information about the time that unit $u$ is able to generate electricity over a one year. The values of $K_{-} A_{u, t}$ are presented in Table 16 in Appendix B. The latter equation (27) introduces the minimum level of electricity generation for unit $u$. In presented model, unit has to produce at least the volume of energy which will be able to cover unit's financial costs $C F I N_{u, t}$ with assumed energy price $E_{-} P R I C E_{t}$. The prospective energy price in long-term perspective is determined by the approximate marginal costs of electricity generation. It is calculated exogenously as the result of several iterations of model execution.

$$
\begin{aligned}
& \forall u \in U, t \in T \quad E_{u, t} \leq K_{-} A_{u, t} \cdot P_{-} I_{u, t} \cdot Y \quad \text { (excluding wind and } P V \text { ) } \\
& \forall u \in U, t \in T \quad E_{u, t} \geq \text { CFIN }_{u, t} / E_{-} P R I C E_{t} \quad \text { (excluding wind and PV) }
\end{aligned}
$$

Formula (28) stands for electricity generation of wind and PV units. In long horizon, their energy production is based on average rates of wind speed or solar radiation intensity. It is represented by availability factor. As the result, the annual electricity generation $E \_R E S_{u, ", t}$ of wind and PV cannot be optimized itself and depends on their installed power $\left(P_{-} I_{-} R E S_{u^{\prime \prime}, t}\right.$ is a continues variable) and availability factor.

$$
\forall u^{\prime \prime \prime} \in U^{\prime \prime \prime}, t \in T \quad E_{-} R E S_{u^{\prime \prime \prime}, t}=K_{-} A_{u^{\prime \prime \prime}, t} \cdot P_{-} I_{-} R E S_{u^{\prime \prime \prime}, t} \cdot Y \quad \text { (for wind and } P V \text { ) }
$$

The energy production for nCDGUs (CHPs and industrial units) is implemented as a parameter according to formula (29).

$$
\forall t \in T \quad E_{-} N C D G U_{t}=K_{-} A_{-} N C D G U_{t} \cdot P_{-} I_{-} N C D G U_{t} \cdot Y \quad \text { (for nCDGUs) }
$$

The presented model includes the minimum requirement for the electricity generation by RES, presented in (30). The minimum RES' energy production can be easily adapted to scenario, e.g. it can follow the EU targets.

$$
\forall t \in T \quad \sum_{u^{\prime \prime \prime} \in U^{\prime \prime \prime}} E_{-} R E S_{u^{\prime \prime \prime}, t} \geq E_{-} R E S_{-} R E Q U I R E M E N T_{t}
$$

The long-term energy mix planning requires consideration of limits for construction of new power capacities, i.e. the maximum amount of capacity which can be commissioned in one year $t$. These constraints are imposed by the technical and economic aspects, e.g. the primary fuel resources in the system and the financial potential of energy companies to construct new power units. The limits for technologies are presented in Table 16 in Appendix B. 


\subsubsection{Short-term power dispatch}

In $e$ Mix, the power units are described not only with maximum and minimum level of power output, but also in terms of power reserves divided into primary (PR), secondary $(\mathrm{SR})$ and tertiary reserve $\left(\mathrm{Y}_{0}\right)$. Technically, unit's

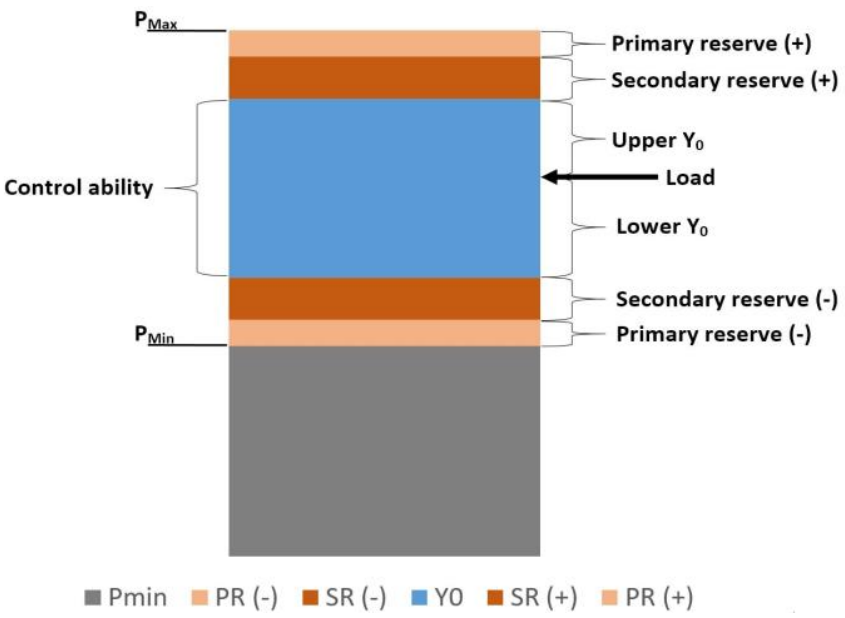

Figure 1. Power reserves ability to serve those reserves depends on technology and applied control systems. PR and SR are fast responding reserves triggered automatically within seconds or minutes, respectively. $\mathrm{Y}_{0}$ is the control ability of a power unit. It should restore PR and SR via change of the operation point of the power plant. The graphical presentation of power reserves is presented in.The flexibility of the power system in $e$ Mix is measured by the amount of reserves included in power units that are available (are in operation) in the system. In the very first approach, power reserves are evaluated in single, representative hour of each year. Representative hour has been assumed as "the worst case" and represents the

peak demand and low share of volatile generation (VG) - wind and PV. Such a case is crucial in relation to power system stability. The low share of VG means that in peak hour wind generation is dispatched in $20 \%$ of its installed power. PV does not appear at all because it is assumed that the peak load occurs in the winter season at evening hour. According to authors' best knowledge and many scenarios carried out, this assumption does not detract from the relevance of final results (the optimal energy mix in long-term perspective) but it brings additional capacity of the fast-responding reserves.

Authors do not investigate the choice of the representative hour in the current research. Further model development and extended analyses of adequacy of power system reserves will require deep analysis of the modelling of daily load profile in long-term planning.

The equation (31) presents the condition, where total dispatched power in the system has to meet the peak load $P_{-} D_{t}$ in each year $t$. According to formula (32), the dispatched power of units in set $U\left(P_{-} D I S P_{u, t}\right)$ is divided into power of thermal CDGUs $\left(P_{-} D I S P_{-} C D G U_{u^{\prime}, t}\right)$, hydro CDGUs $\left(P_{-} D I S P_{-} H Y D C D G U_{u^{\prime \prime}, t}\right)$ and RES $\left(P_{-} D I S P_{-} R E S_{u^{\prime \prime}, t}\right)$. The daily power balance is also complemented by the power of other nCDGUs $\left(P \_D I S P \_N C D G U_{t}\right)$.

$$
\begin{gathered}
\forall t \in T \quad \sum_{u \in U} P_{-} D I S P_{u, t}+P_{-} D I S P_{-} N C D G U_{t}=P_{-} D_{t} \\
\forall t \in T \quad \sum_{u \in U} P_{-} D I S P_{u, t}= \\
\sum_{u^{\prime} \in U^{\prime}} P_{-} D I S P_{-} C D G U_{u^{\prime}, t}+\sum_{u^{\prime \prime} \in U^{\prime \prime}} P_{-} D I S P_{-} H Y D C D G U_{u^{\prime \prime}, t}+\sum_{u^{\prime \prime \prime} \in U^{\prime \prime \prime}} P_{-} D I S P_{-} R E S_{u^{\prime \prime \prime}, t}
\end{gathered}
$$

In order to meet the hourly power balance, only the load of the CDGUs (which are controlled by the TSO) can be adjusted to required level. According to Figure 1, the load of CDGUs has to be located in the $Y_{0}$ area. Its maximal and minimal levels are described in equations (33) and (34).

$$
\begin{array}{cc}
\forall u^{\prime} \in U^{\prime}, \forall t \in T \quad & P_{-} D I S P_{-} C D G U_{u \prime, t} \leq \\
& P_{-} M A X_{u \prime, t}-\left(P R I M A R Y \_R E S E R V E_{u^{\prime}, t}+S E C O N D A R Y \_R E S E R V E_{u^{\prime}, t}\right) \\
\forall u^{\prime} \in U^{\prime}, \forall t \in T \quad & P_{-} D I S P_{-} C D G U_{u \prime, t} \geq \\
& P_{-} M I N_{u \prime, t}+P R I M A R Y \_R E S E R V E_{u^{\prime}, t}+S E C O N D A R Y \_R E S E R V E_{u^{\prime}, t}
\end{array}
$$

The load of other units (RES and nCDGUs) is implemented as must-run. The share of these units is defined by the percentile factor $K_{-} D I S P$, which determines the dispatched power according to the installed power $P \_I$. For 
example, the formula (35) presents the dispatched power for RES. The value of factor $K \_D I S P$, according to particular technology, is presented in Table 16 in Appendix B.

$$
\forall u^{\prime \prime \prime} \in U^{\prime \prime \prime}, \forall t \in T \quad P_{-} D I S P_{-} R E S_{u \prime \prime \prime, t}=K_{-} D I S P_{u \prime \prime \prime} \cdot P_{-} I_{-} R E S_{u \prime \prime \prime, t}
$$

The formula (36) presents the must-run constraint for CDGUs. In power system there are units, which have to be in operation to ensure stable parameters of the system, i.e. voltage levels, short-circuit power levels. Constraint (36) involves the required level of must-runs' power $P_{-} C D G U_{-} M U S T R U N_{t}$.

$$
\forall t \in T \quad \sum_{u^{\prime} \in U^{\prime}} P_{-} D I S P_{-} C D G U_{u^{\prime}, t} \geq P_{-} C D G U_{-} M U S T R U N_{t}
$$

The equations (37)-(39) present the requirements concerning the power reserves, which are implemented by UCTE Operation Handbook. The formula (37) presents that total power capacity, included in primary reserves of available CDGUs, has to be greater than $250 \mathrm{MW}$. The requirement (38) defines that total capacity of secondary reserve has to exceed the double value of power of the largest power unit in the system. The upper tertiary reserve $\mathrm{Y}_{0}$, included in (39), has to be greater or equal to required level expressed by the percentile factor $K_{-} R E S E R V E \_D I S P_{t}$ multiplied by actual load $P_{-} D_{t}$.

$$
\begin{gathered}
\forall t \in T \sum_{u^{\prime} \in U^{\prime}} P R I M A R Y_{-} R E S E R V E_{u^{\prime}, t}>250 M W \\
\forall t \in T \sum_{u^{\prime} \in U^{\prime}} S E C O N D A R Y_{-} R E S E R V E_{u^{\prime}, t}>2 \cdot \max \left\{P_{-} A_{u, t}\right\} \\
\forall t \in T \sum_{u^{\prime} \in U^{\prime}} Y O_{-} U P_{u \prime, t} \geq K_{-} P R E S E R V E_{-} D I S P_{t} \cdot P_{-} D_{t}
\end{gathered}
$$

The constraints (40) and (41) presents the connection between the required level of flexibility in the system (expressed by the capacity of power reserves) and possible deviations for the forecast of volatile generation sources. The power of upward and downward regulation of tertiary reserve $\left(Y_{O_{-}} U P_{u^{\prime}, t}\right.$ and $\left.Y_{O_{-}} D O W N_{u^{\prime}, t}\right)$ has to exceed the prospective variations of wind and PV units $\Delta V G_{t}$. Such a formulation provides the required level of flexible capacity, which can balance the VG.

$$
\begin{gathered}
\forall t \in T \quad \sum_{u^{\prime} \epsilon U^{\prime}} Y o_{-} U P_{u \prime, t} \geq \sum_{u^{\prime \prime \prime} \epsilon U^{\prime \prime \prime}} \Delta V G_{u^{\prime \prime \prime}, t} \\
\forall t \in T \quad \sum_{u^{\prime} \in U^{\prime}} Y o_{-} D O W N_{u \prime, t} \geq \sum_{u^{\prime \prime \prime} \epsilon U^{\prime \prime \prime}} \Delta V G_{u^{\prime \prime \prime}, t}
\end{gathered}
$$

The formula (42) presents the $\Delta V G_{t}$ that is introduced as a share of installed power $P_{-} I \_R E S_{u}{ }^{\prime \prime},{ }_{,}$. The value of percentile factor $K_{-} V G_{-} D I S P_{t}$ can be adapted to the needs of simulation scenarios.

$$
\forall u^{\prime \prime \prime} \in U^{\prime \prime \prime}, \forall t \in T \quad \Delta V G_{u^{\prime \prime \prime}, t}=K_{-} V G_{-} D I S P_{t} \cdot P_{-} I_{-} R E S_{u^{\prime \prime \prime}, t}
$$

\section{Case study}

In order to prove the quality and correctness of calculations, the model has been calibrated with parameters and data of Polish power system [52] and external manuscripts of generation parameters (the most important data sets are presented in the Appendix B). Furthermore, a four-simulation scenario was defined and calculated. Description of the scenarios is presented in this section.

\subsection{Scenarios definition}

Several simulation scenarios were defined to investigate how the novel elements, taken into account in the energy mix optimization model, affect the results. 
Worth highlighting is that the model's objective is not to provide the forecast of the power system development - it is very complex issue that cannot be accomplished with a single tool for energy system modelling. The objective of the case study presented is to answer a question - what is the impact of the defined input parameters on the energy mix in long-term horizon. It is the reason why, e.g. the price of $\mathrm{CO}_{2}$ emission allowances or fuel prices are not modeled by the price trajectory, but by a single value. Because every continuous assumption introduces high uncertainty, in most cases it is better to find an answer how single decisions affect the future mix, than try to develop a complex forecast.

Reference scenario $\mathrm{S} 1$ incorporates the moderate price of $\mathrm{CO}_{2}$ emission allowances $-25 € / t C \mathrm{O}_{2}$. Current price is around $8 € / \mathrm{tCO}_{2}$, but the regulation in the EU ETS, e.g. introduction of Market Stability Reserve (MSR), should increase the price. Gas price $\left(400 \$ / 1000 m^{3}\right)$ is assumed below the current price in Poland $\left(430 \$ / 1000 \mathrm{~m}^{3}\right)$, but the decrease is in line with World Bank forecasts. RES requirement is based on the current Polish Energy Policy - 19\% of total electricity generation in 2020. Scenario S2 assumes the lower gas price $\left(250 \$ / 1000 m^{3}\right)$. The $\mathrm{S} 3$ presents how the energy mix should be represented if Poland will limit its $\mathrm{CO}_{2}$ emissions in the power sector by $43 \%$ in relation to the base year 2005 (as agreed by European Commission in October 2014). Such a reduction should be reached not by the EU direct limitations, but through the increase in $\mathrm{CO}_{2}$ allowances price in properly operated EU ETS. Therefore, the scenario S4 presents the ultra-high price for $\mathrm{CO}_{2}$ allowances $-80 € / t C O_{2}$. For all of the scenarios, the percentile factor $K_{-} V G_{-} D I S P_{t}$ (that denotes the possible deviations for the forecast of volatile generation sources (wind and PV)) equals $40 \%$ regarding to the VG's installed power.

Table 7 presents the simulated scenarios. S1 reflects the predicted status of the Polish power system in 2020. The starting year of the optimization is moved from 2015 to 2020 in order to mitigate an initial period, where decisions to build particular units have been already taken. The existing units (commissioned before 2020) are included in the energy mix within their remaining lifetime. The data of existing units in Polish power system is based on the technology development plan for Poland prepared by the national institutions such as Transmission System Operator, Energy Market Agency, Ministry of Economy and connection permissions obtained by the investors from TSO.

Table 7. Scenario definition

\begin{tabular}{lcccccc}
\hline No & Description & $\begin{array}{c}\mathbf{C O} \\
\text { price } \\
{\left[\mathbf{E} / \mathbf{t C O} \mathbf{C}_{2}\right]}\end{array}$ & $\begin{array}{c}\text { Forced CO2 } \\
\text { emission } \\
\text { reduction }\end{array}$ & $\begin{array}{c}\text { Gas price } \\
{\left[\mathbf{\$} / \mathbf{1 0 0 0 m}^{3}\right]}\end{array}$ & $\begin{array}{c}\text { RES } \\
\text { requirement }\end{array}$ & K_VG_DISP \\
\hline S1 & Reference scenario & 25 & - & 400 & $19 \%$ (all horizon) & $40 \%$ \\
\hline S2 & Low gas price & 25 & - & 250 & $19 \%$ (all horizon) & $40 \%$ \\
\hline S3 & Impact of forced $\mathrm{CO}_{2}$ emission limitation & 25 & $43 \%$ in 2030 & 400 & $19 \%$ (all horizon) & $40 \%$ \\
\hline S4 & Ultra-high price of $\mathrm{CO}_{2}$ emission allowances & 80 & - & 400 & $19 \%$ (all horizon) & $40 \%$ \\
\hline
\end{tabular}

\subsection{Input data}

The input data are presented in Appendix B. Assumptions about prospective energy and power demand are in - Figure 14 and Table 14 The parameters of particular technologies are presented in Table 15-Table 18. Table 19 includes parameters used for WACC estimation.

\subsection{Computational performance}

The calculations presented in this paper were performed using the PC equipped with processor Intel Pentium i7 quad core $3.6 \mathrm{GHz}$ and memory $32 \mathrm{~GB}$ RAM. The optimization software was FICO ${ }^{\circledR}$ Xpress Optimization Suite 7.9.0. Table 8 presents the parameters defining size of optimization model.

Table 8. Parameters defining size of optimization model 


\begin{tabular}{ccccc}
\hline No. of constraints & $\begin{array}{c}\text { No. of nonzero } \\
\text { elements }\end{array}$ & $\begin{array}{c}\text { No. of binary } \\
\text { variables }\end{array}$ & $\begin{array}{c}\text { No. of continuous } \\
\text { variables }\end{array}$ & $\begin{array}{c}\text { No. of semi-continuous } \\
\text { variables }\end{array}$ \\
\hline 55037 & 510691 & 1199 & 68014 & 155 \\
\hline
\end{tabular}

Table 9 and Table 10 include the analysis of the computational performance of the model with different termination criterion of the calculations. The former table includes the results for computational time obtained within defined relative gap: $0.5 \%$ and $0.2 \%$. The latter presents the relative gap of the calculations obtained within the defined computational time: $1 \mathrm{~h}$ and $3 \mathrm{~h}$.

The results presented in this paper are obtained for the model where stop criterion of the calculations was the relative gap defined at the level of $0.2 \%$. In

Table 9 it can be observed that computational time is lower than $130 \mathrm{~s}$.

Table 9. Results for the CPU time obtained within the required relative gap defined $-0.5 \%$ and $0.2 \%$

\begin{tabular}{ccccccccc} 
& \multicolumn{3}{c}{ Defined relative gap $\mathbf{0 . 5 \%}$} & \multicolumn{4}{c}{ Defined relative gap $=\mathbf{0 . 2 \%}$} \\
\cline { 2 - 9 } & $\mathrm{S} 1$ & $\mathrm{~S} 2$ & $\mathrm{~S} 3$ & $\mathrm{~S} 4$ & $\mathrm{~S} 1$ & $\mathrm{~S} 2$ & $\mathrm{~S} 3$ & $\mathrm{~S} 4$ \\
\hline CPU time & $13 \mathrm{~s}$ & $4 \mathrm{~s}$ & $20 \mathrm{~s}$ & $5 \mathrm{~s}$ & $123 \mathrm{~s}$ & $12 \mathrm{~s}$ & $21 \mathrm{~s}$ & $5 \mathrm{~s}$ \\
\hline
\end{tabular}

Table 10. Results for the relative gap obtained within the maximal CPU time defined $-1 \mathrm{~h}$ and $3 \mathrm{~h}$

\begin{tabular}{|c|c|c|c|c|c|c|c|c|}
\hline & \multicolumn{4}{|c|}{ Defined CPU time $=1 \mathrm{~h}$} & \multicolumn{4}{|c|}{ Defined CPU time $=3 \mathrm{~h}$} \\
\hline & S1 & S2 & S3 & S4 & S1 & S2 & S3 & S4 \\
\hline Relative gap & $0.13 \%$ & $0.06 \%$ & $0.09 \%$ & $0.04 \%$ & $0.12 \%$ & $0.06 \%$ & $0.08 \%$ & $0.04 \%$ \\
\hline
\end{tabular}

More detailed analysis of the computational performance of the model $e$ Mix is presented in [1] where apart from relative gap and computational time, the impact of the size of the power system (the various levels of the peak demand) on the obtained results was evaluated.

\section{Results and discussion}

Figure 2 - Figure 9 present installed power in $M W$ (left column) and corresponding electricity generation in $T W h$ (right column) by scenarios (in rows) S1, S2, S3, S4. Each band represents capacity or generation grouped according to technology. Figure 10 represents the power dispatch for peak hour and Figure 11 includes power reserves in $M W \_h$. The Figure 12 presents the total $\mathrm{CO}_{2}$ emissions, while the Figure 13 stands for marginal cost for electricity generation. Additionally, Table 20 and Table 21 in Appendix C include the results of the available capacity and energy production represented by numbers.

\subsection{Scenario results}

In the first decade, the structure of the installed power in S1 is determined by the existing (before 2020), coalfired units. The majority of capacity is installed in hard coal units. However, at the begging of the optimization horizon, about $2.5 \mathrm{GW}$ of new gas units enter the mix due to requirements for power reserves. After 2030 old hard coal units are decommissioned and required capacity is replaced by technology with low CAPEX - gas power plants, which provide the additional power reserves. In 2050 the capacity of gas units is higher than the sum of lignite and hard coal units' capacity. RES enter the mix despite high costs, only to meet the requirement of the $19 \%$ share in energy production. It can be noticed that there is a significant overcapacity in RES, but it results from the availability factor of wind turbines (10\%). It should be emphasised that in current model's version, RES enter the mix due to the market cost optimization because subsidies are not considered. As the $\mathrm{CO}_{2}$ allowances price equals $25 € / t C \mathrm{O}_{2}$, the nuclear units are not constructed.

In case of electricity generation, it is worth highlighting that $25 € / t \mathrm{CO}_{2}$ is not enough to make the hard coal units competitive. The lignite units have the most significant share in all time horizon. After 2030, there is a 
growth in electricity generation of gas units but despite the large share in the installed capacity their generation is relatively low. It indicates that these units are mostly to cover the peak load. The RES cover $19 \%$ of total electricity generation according to the requirement.

The low price of gas in S2 $\left(250 \$ / 1000 \mathrm{~m}^{3}\right)$ results in the significant increase in both installed power and electricity generation of gas units. After decommissioning of the majority of existing coal-fired units in 2030, the gas units become the dominant technology.

Scenario S3 answers the question how the energy mix should look like, in order to achieve in 2030 the $43 \%$ reduction of $\mathrm{CO}_{2}$ emission in power sector in relation to 2005. It would also require switching to gas (it would be the least expensive solution out of other options such as RES or nuclear power plants). However, the level of electricity generation of gas units can be significantly lower than in scenario S2. It means, that much better environmental effects in case of $\mathrm{CO}_{2}$ emissions reduction can be achieved by searching for the low-priced gas contracts and new import sources.

In S4, high emissive technologies, such as lignite, are permanently out of the mix. Even such a high $\mathrm{CO}_{2}$ emission allowances price does not make the nuclear units cost-effective (according to many scenarios carried out, with the price over $90 € / t \mathrm{CO}_{2}$ nuclear units enter the mix). High CAPEX of nuclear units with the longest construction time (7 years) makes the nuclear power plant the most expensive technology nowadays.

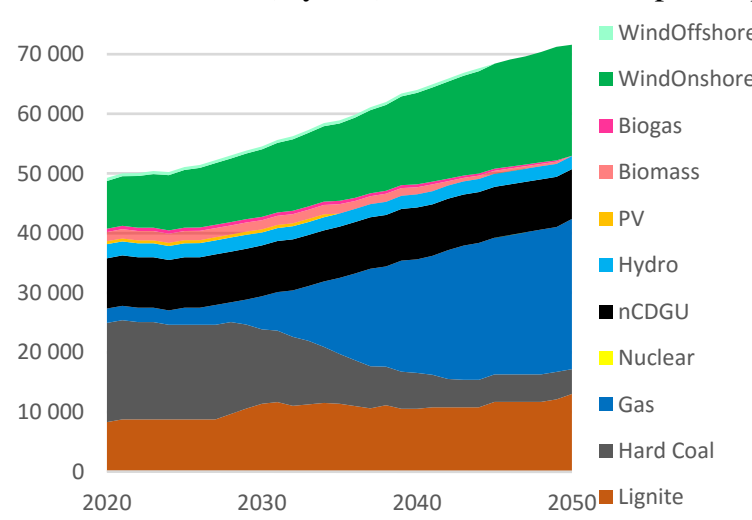

Figure 2. Installed power in MW (S1)

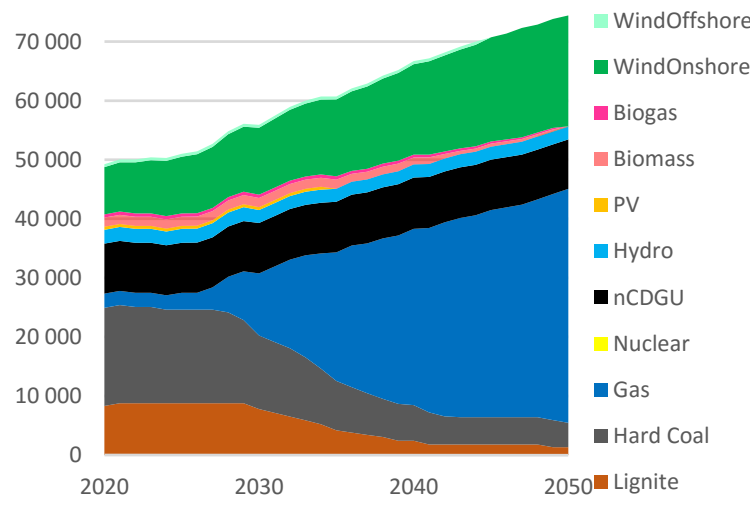

Figure 4. Installed power in MW (S2)

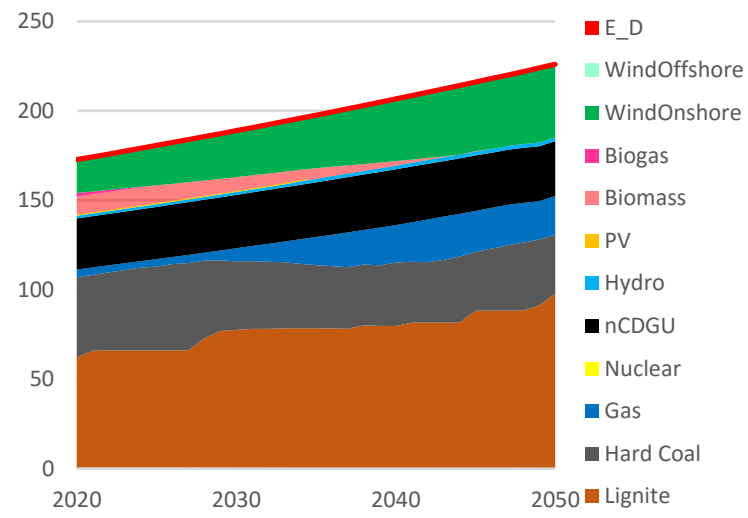

Figure 3. Electricity generation in TWh (S1)

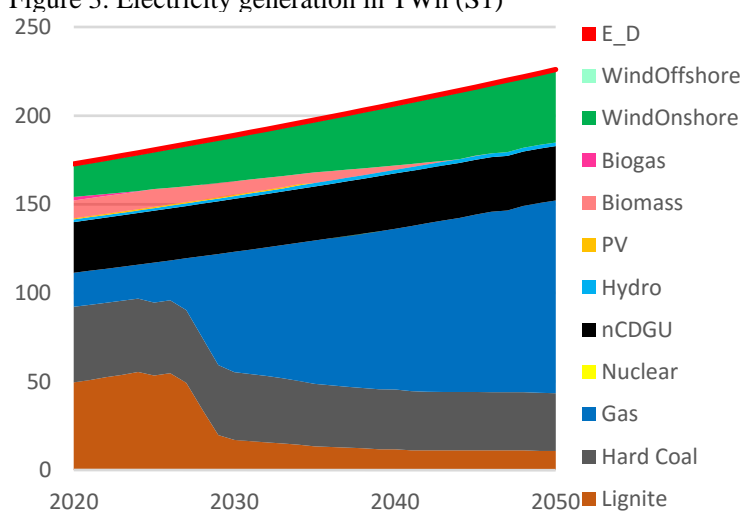

Figure 5. Electricity generation in TWh (S2) 


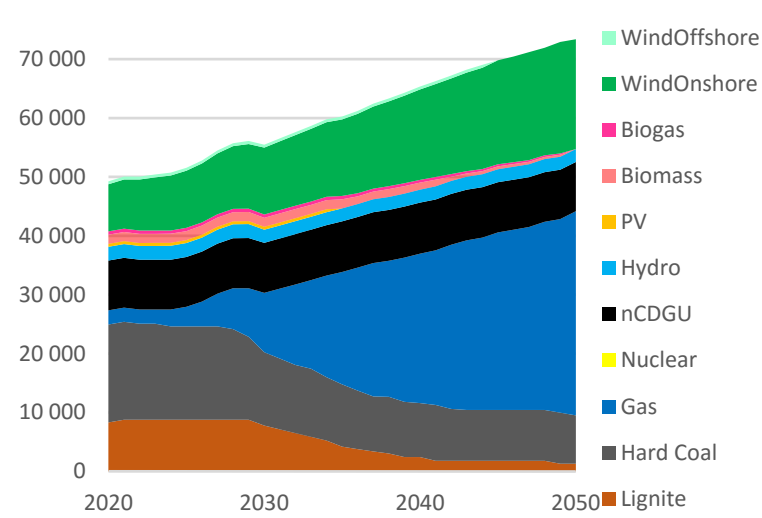

Figure 6. Installed power in MW (S3)

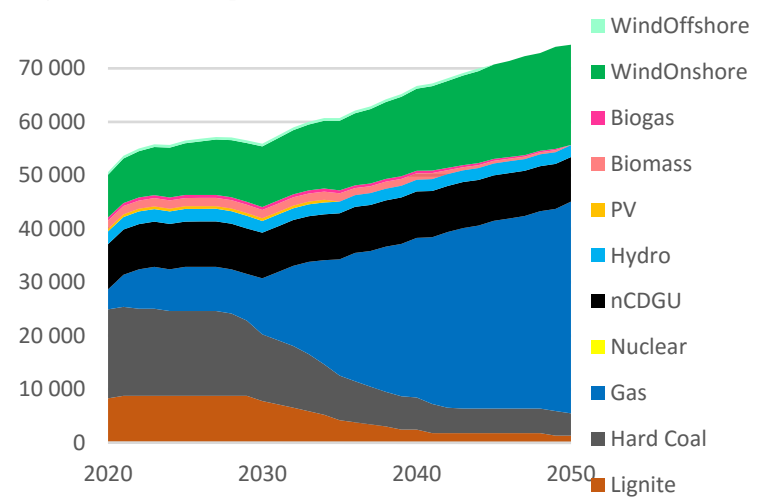

Figure 8. Installed power in MW (S4)

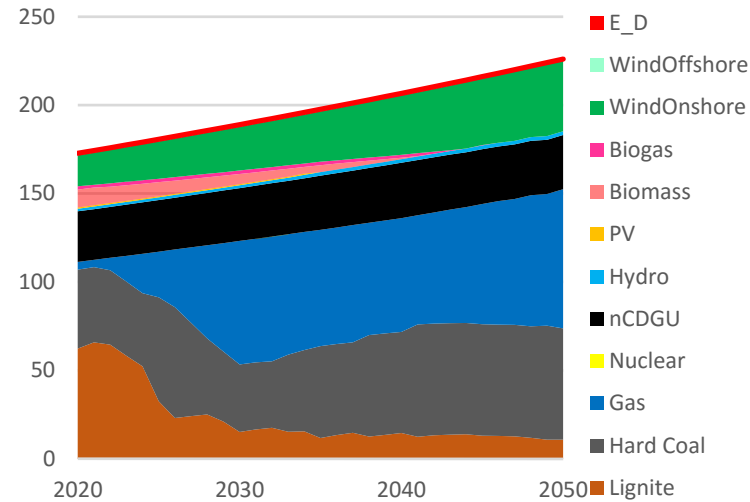

Figure 7. Electricity generation in TWh (S3)

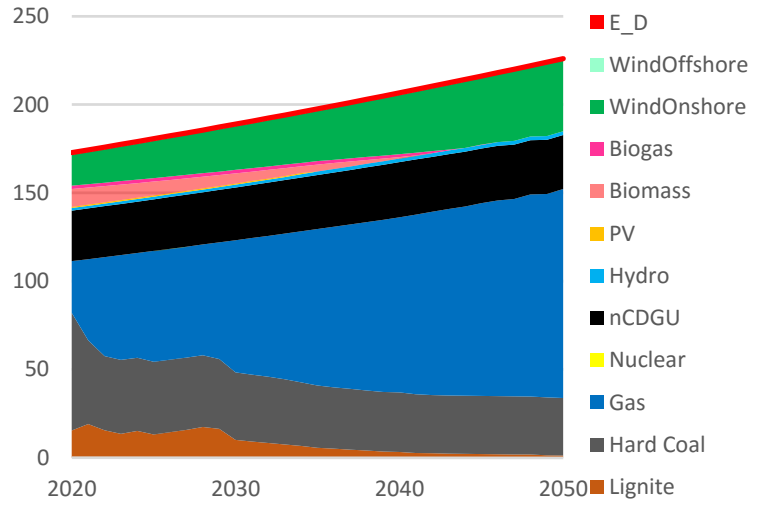

Figure 9. Electricity generation in TWh (S4)

The Figure 10 presents the power dispatch for peak hour for all scenarios. According to assumptions, the share of VG is kept at low level. Wind power is dispatched in $20 \%$ of its total capacity. PV does not appear at all. The other RES are dispatched with their maximum available power. As a result, over $70 \%$ of peak load must be covered by conventional CDGUs.

In S1, where the majority of electricity generation comes from lignite units (Figure 3), these units are base ones. The dispatched power of hard coal units gradually decreases within time horizon and they are consequently substituted by gas units. This move is also strengthened by the need of power reserves. This trend is repeated in all scenarios, but in S2-S4 it is more intensive.

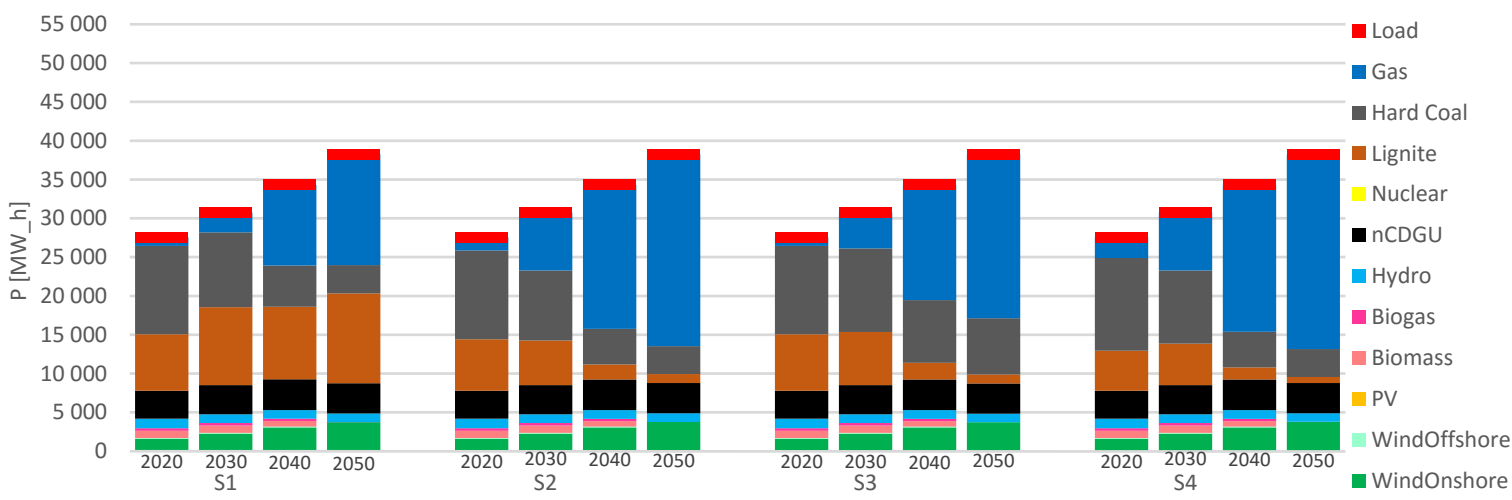

Figure 10. Power dispatch by scenario and year

Figure 11presents the cumulative power of CDGUs, which is presented as technical minimum, primary (PR), secondary (SR) and tertiary reserve $\left(\mathrm{Y}_{0}\right)$ (as in scenarios, the load is located in the middle of the control ability 
area. It guarantees the required value of upward and downward $\mathrm{Y}_{0}$, which is necessary to balance the fluctuations of daily load and variations of VG. Also the PR and SR are above required level. It can be noticed that in $\mathrm{S} 1$ the amount of reserves (especially PR and SR) is slightly smaller than in other scenarios. It is due to large share of lignite units in S1, which are characterized by the lower value of power located in reserves than gas units (which dominates the power dispatch in S2-S4). In comparison to Figure 10 must be in operation to ensure the required level of reserves. must be in operation to ensure the required level of reserves. be in operation to ensure the required level of reserves.

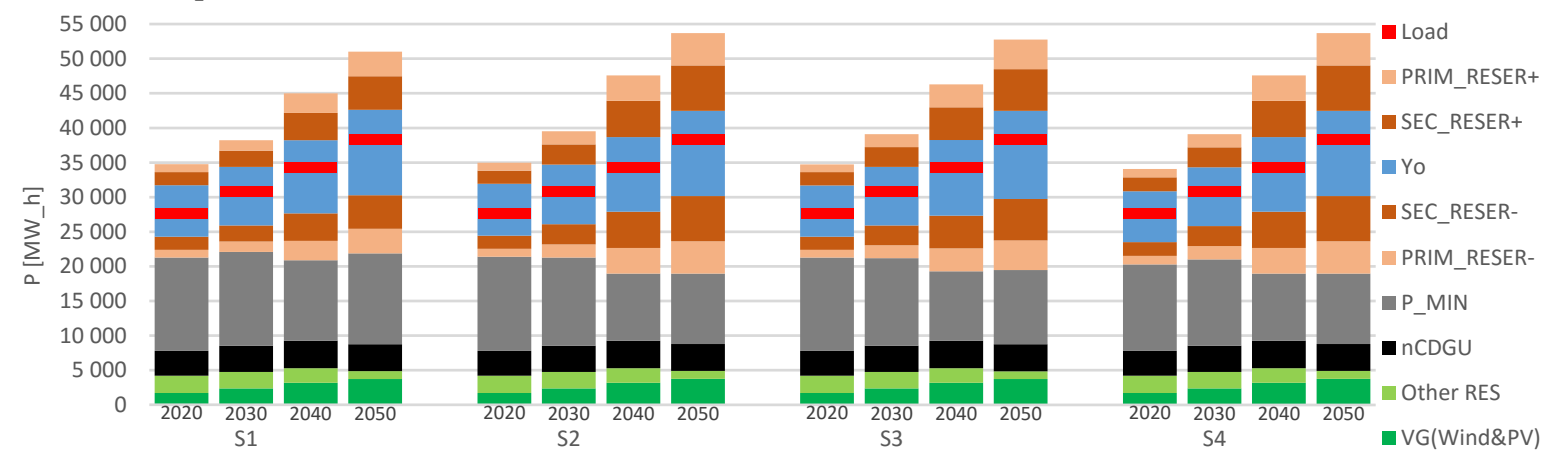

Figure 11. Power reserves by scenario and year

Taking into account the $\mathrm{CO}_{2}$ emissions (Figure 12), scenario S3 can play a role of reference scenario. It assumes the forced reduction of $\mathrm{CO}_{2}$ emissions. However, in real power system it should be achieved by properly organized EU ETS, which will increase the price of $\mathrm{CO}_{2}$ emissions allowances. In S4, it is presented that the very high price $\left(80 € / \mathrm{tCO}_{2}\right.$ ) can lead to more satisfying results in terms of environmental goals. The surprising results are obtained by scenario $\mathrm{S} 2$ because $\mathrm{CO}_{2}$ emissions are similar to those in $\mathrm{S} 4$. In this case, the reduction is a result of gas price lower than in other scenarios. According to $\mathrm{S} 1$, it is predictable that the power system, which bases on coal technologies (especially lignite) has the highest $\mathrm{CO}_{2}$ emissions.

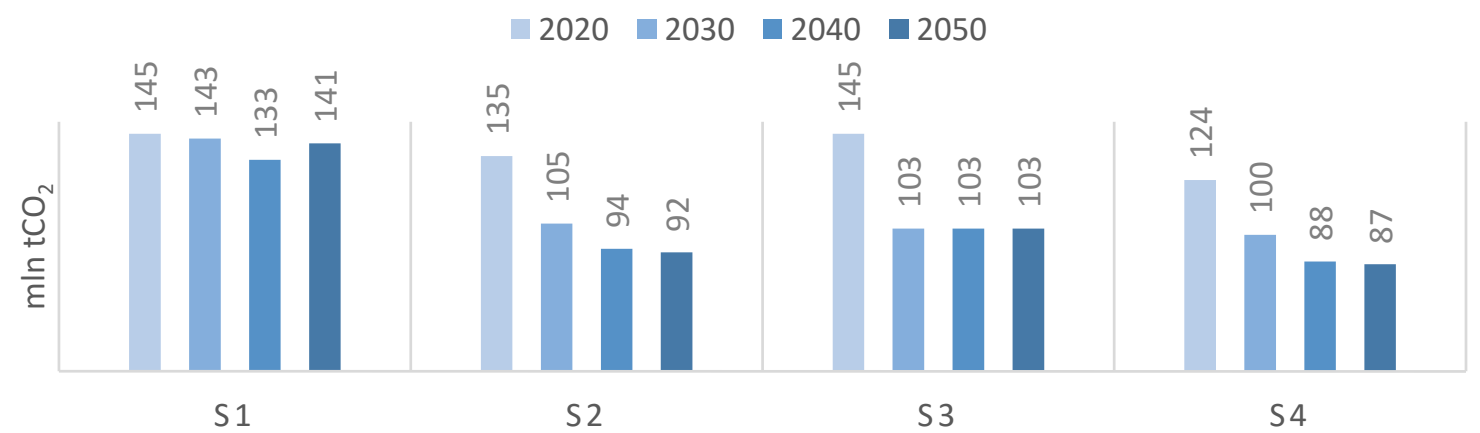

Figure 12. $\mathrm{CO}_{2}$ emissions in power sector by scenario and year

Currently in Poland (in 2015), marginal cost of electricity generation (Figure 13) is not higher than 40$50 € / M W h$. The increase in obtained results is a consequence of necessary investments in new power units. What is interesting, in $\mathrm{S} 2$ the marginal cost is the lowest and the $\mathrm{CO}_{2}$ emissions are at relatively low level (Figure 12). This shows the importance of impact of the gas price on the future energy mix. The relatively small difference in marginal cost between $\mathrm{S} 1$ and $\mathrm{S} 3$ shows the cost of the $\mathrm{CO}_{2}$ emissions limitation according to EU 2030 targets. The large difference in $\mathrm{CO}_{2}$ emissions in these scenarios (about $40 \mathrm{mln} t \mathrm{CO}_{2}$ in 2050) can be achieved with marginal cost higher by $3 € / M W h$. The highest marginal cost among scenarios is in $\mathrm{S} 4$, which is an effect of the very high $\mathrm{CO}_{2}$ emissions allowances price. 


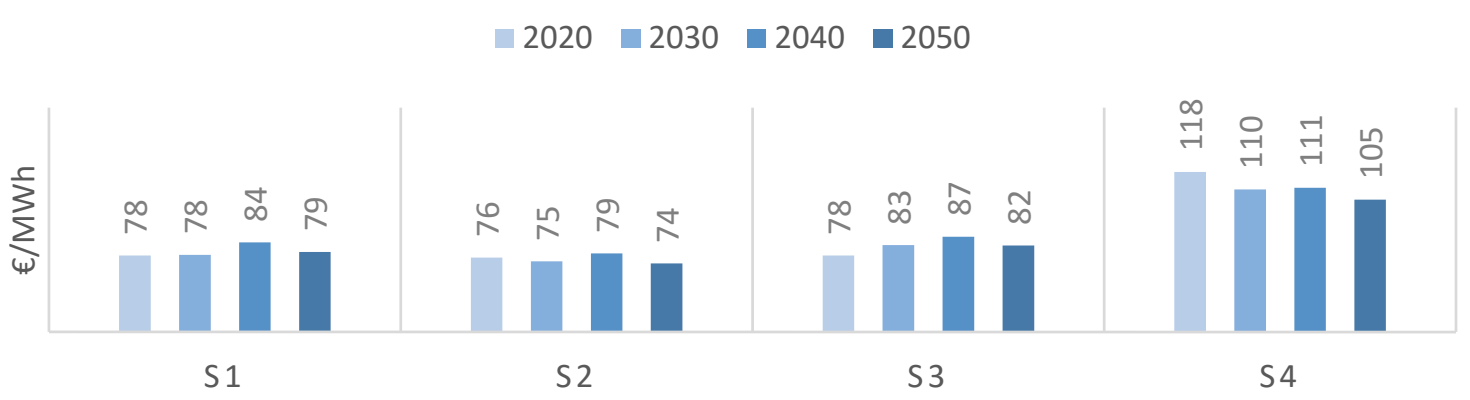

Figure 13. Marginal cost of electricity generation

\section{Conclusions}

The paper presents a novel approach to long-term energy mix optimization, which incorporates the MILP and links the long-term investment planning with short-term operation of the power system. Presented optimization model determines the energy mix, where large power units are considered individually with representation of full financial costs of construction. The model includes requirements for power reserves: primary, secondary and tertiary.

The presented model allows for consideration of short term power system operation (unit commitment and dispatch) in long term generation expansion planning. Such methodology enables the evaluation of the need for power reserves, which will be able to balance the fluctuations of daily load and instability caused by variable RES. Additionally, it allows for connection of expansion of intermitted generation with firm capacity. As a result, it leads to reliable energy mix, which has higher marginal cost of electricity generation but is more flexible and provides higher level of security of supply.

Consideration of financial costs provides better view on differences between costs of each technology and, what follows, future cost of electricity. Assuming project finance as the financing scheme and share of equity and loan, it can be noticed that differences between the least expensive and the most expensive technology rise. Hence, the real costs of technologies with high investment costs and long construction period are much higher in comparison to shortly commissioned units with low investment costs at level much higher than expected. It leads to more reliable results.

The results indicate the importance of the gas technology in the future energy mix. The advantages of gas power units are (a) the use as a backup capacity for intermitted RES generation because gas technology can provide the largest share of power reserves and (b) the relatively low $\mathrm{CO}_{2}$ emissions compared to other firm, conventional technologies (coal-fired units). The decrease in the gas price provides very positive results in case of $\mathrm{CO}_{2}$ emissions and, at the same time, the lowest marginal cost of electricity generation among scenarios.

Further authors' research will include modelling of the representative daily load curve with higher resolution, maintaining computational efficiency. To obtain the more precise information about the need of the power reserves, the time span should be extended. Therefore, it is important to develop the method for representing of an equivalent power demand curve for energy system modelling.

\section{Acknowledgements}

The authors would like to express the gratitude to the $\mathrm{FICO}^{\circledR}$ corporation for programming support and provision of academic licenses for Xpress Optimization Suite to Institute of Electrical Power Engineering at Lodz University of Technology.

The authors would like to thank Prof. Wladysław Mielczarski for his supervisory and the paper review. 
The authors would like to thank the Lodz University of Technology Computer Centre as the calculations mentioned in this paper were performed using the PLATON project's infrastructure.

The authors would like to thank the Department of Energy at the Ministry of Energy (former Ministry of Economy) for invaluable remarks from perspective of government administration and policy makers.

\section{References}

[1] W. Lyzwa, M. Wierzbowski, and B. Olek, "MILP formulation for energy mix optimization," IEEE Trans. Ind. Informatics, vol. 3203, no. c, pp. 1-1, 2015.

[2] S. Pfenninger, A. Hawkes, and J. Keirstead, "Energy systems modeling for twenty-first century energy challenges," Renew. Sustain. Energy Rev., vol. 33, pp. 74-86, May 2014.

[3] A. Herbst, F. A. Toro, F. Reitze, and E. Jochem, "Introduction to Energy Systems Modelling,” Swiss J. Econ. Stat., vol. 148, no. II, pp. 111-135, 2012.

[4] B. C. Erdener, K. A. Pambour, R. B. Lavin, and B. Dengiz, "An integrated simulation model for analysing electricity and gas systems," Int. J. Electr. Power Energy Syst., vol. 61, pp. 410-420, Oct. 2014.

[5] D. Connolly, H. Lund, B. V. Mathiesen, and M. Leahy, "A review of computer tools for analysing the integration of renewable energy into various energy systems," Appl. Energy, vol. 87, no. 4, pp. 1059-1082, Apr. 2010.

[6] M. Wierzbowski, B. Olek, and W. Łyżwa, "Energy Mix Optimisation in the EU Energy Policy Context (in Polish)," Rynek Energii, vol. 5, no. 5, pp. 23-31, 2014.

[7] W. Łyżwa, B. Olek, and M. Wierzbowski, "Energy Mix Optimization - simulations in eMix model (in Polish), "vol. 6, no. 6, pp. 25-32, 2014.

[8] M. Welsch, P. Deane, M. Howells, B. Ó Gallachóir, F. Rogan, M. Bazilian, and H.-H. Rogner, "Incorporating flexibility requirements into long-term energy system models - A case study on high levels of renewable electricity penetration in Ireland," Appl. Energy, vol. 135, pp. 600-615, Dec. 2014.

[9] J. P. Deane, A. Chiodi, M. Gargiulo, and B. P. Ó Gallachóir, "Soft-linking of a power systems model to an energy systems model," Energy, vol. 42, no. 1, pp. 303-312, Jun. 2012.

[10] M. Welsch, M. Howells, M. R. Hesamzadeh, B. Ó Gallachóir, P. Deane, N. Strachan, M. Bazilian, D. M. Kammen, L. Jones, G. Strbac, and H. Rogner, "Supporting security and adequacy in future energy systems: The need to enhance long-term energy system models to better treat issues related to variability," Int. J. Energy Res., p. n/a-n/a, Oct. 2014.

[11] M. Welsch, M. Howells, M. Bazilian, J. F. DeCarolis, S. Hermann, and H. H. Rogner, "Modelling elements of Smart Grids Enhancing the OSeMOSYS (Open Source Energy Modelling System) code,” Energy, vol. 46, no. 1, pp. 337-350, Oct. 2012.

[12] A. B. Borison and P. A. Morris, "An Efficient Approach to the Optimal Static Generation Mix Problem," IEEE Power Eng. Rev., vol. PER-4, no. 3, pp. 35-36, Mar. 1984.

[13] E. Oatman and L. Hamant, “A Dynamic Approach to Generation Expansion Planning," IEEE Trans. Power Appar. Syst., vol. PAS-92, no. 6, pp. 1888-1897, Nov. 1973.

[14] N. U. Ahmed and Q. Ahsan, “A dynamic model for generation expansion planning,” Electr. Power Syst. Res., vol. 9, no. 1, pp. 79-86, Jun. 1985.

[15] A. Ramos, I. J. Perez-Arriaga, and J. Bogas, “A nonlinear programming approach to optimal static generation expansion planning,” IEEE Trans. Power Syst., vol. 4, no. 3, pp. 1140-1146, 1989.

[16] W. J. Hobbs, G. Hermon, S. Warner, and G. B. Shelbe, "An enhanced dynamic programming approach for unit commitment," IEEE Trans. Power Syst., vol. 3, no. 3, pp. 1201-1205, Aug. 1988.

[17] B. Alizadeh and S. Jadid, "A dynamic model for coordination of generation and transmission expansion planning in power systems,” Int. J. Electr. Power Energy Syst., vol. 65, pp. 408-418, Feb. 2015.

[18] C. Yuan, C. Gu, F. Li, and B. Kuri, "New Problem Formulation of Emission Constrained Generation Mix," IEEE Trans. Power Syst., vol. 28, no. 4, pp. 4064-4071, 2013.

[19] A. I. Tolis and A. A. Rentizelas, "An impact assessment of electricity and emission allowances pricing in optimised expansion planning of power sector portfolios," Appl. Energy, vol. 88, no. 11, pp. 3791-3806, Nov. 2011.

[20] A. Marin and J. Salmeron, "Electric capacity expansion under uncertain demand: decomposition approaches," IEEE Trans. Power Syst., vol. 13, no. 2, pp. 333-339, May 1998.

[21] J. Sirikum, a Techanitisawad, and V. Kachitvichyanukul, "A new efficient GA-benders' decomposition method: For power generation expansion planning with emission controls," IEEE Trans. Power Syst., vol. 22, no. 3, pp. 1092-1100, 2007.

[22] F. Careri, C. Genesi, P. Marannino, M. Montagna, S. Rossi, and I. Siviero, "Generation expansion planning in the age of green economy," IEEE Trans. Power Syst., vol. 26, no. 4, pp. 2214-2223, 2011.

[23] S. A. Farghal, R. M. El-Dewieny, and M. Roshdy Abdel Aziz, "Generation Expansion Planning Using the Decision Tree Technique,” Electr. Power Syst. Res., vol. 13, no. 1, pp. 59-70, Aug. 1987.

[24] N. E. Koltsaklis, A. S. Dagoumas, G. M. Kopanos, E. N. Pistikopoulos, and M. C. Georgiadis, "A spatial multi-period longterm energy planning model: A case study of the Greek power system," Appl. Energy, vol. 115, pp. 456-482, Feb. 2014.

[25] S. Ahmed, M. Elsholkami, A. Elkamel, J. Du, E. B. Ydstie, and P. L. Douglas, "Financial risk management for new technology integration in energy planning under uncertainty," Appl. Energy, vol. 128, pp. 75-81, Sep. 2014.

[26] C. Barteczko-Hibbert, I. Bonis, M. Binns, C. Theodoropoulos, and A. Azapagic, "A multi-period mixed-integer linear optimisation of future electricity supply considering life cycle costs and environmental impacts," Appl. Energy, vol. 133, pp. 317-334, Nov. 2014.

[27] A. J. C. Pereira and J. T. Saraiva, "Generation expansion planning (GEP) - A long-term approach using system dynamics and genetic algorithms (GAs),” Energy, vol. 36, no. 8, pp. 5180-5199, Aug. 2011.

[28] H. Zhu, W. W. Huang, and G. H. Huang, "Planning of regional energy systems: An inexact mixed-integer fractional programming model,” Appl. Energy, vol. 113, pp. 500-514, Jan. 2014.

[29] M. Avetisyan, D. Bayless, and T. Gnuni, "Optimal expansion of a developing power system under the conditions of market 
[30] R. Cheng, Z. Xu, P. Liu, Z. Wang, Z. Li, and I. Jones, “A multi-region optimization planning model for China's power sector," Appl. Energy, vol. 137, pp. 413-426, Jan. 2015.

[31] D. Zhang, P. Liu, L. Ma, Z. Li, and W. Ni, "A multi-period modelling and optimization approach to the planning of China's power sector with consideration of carbon dioxide mitigation," Comput. Chem. Eng., vol. 37, pp. 227-247, Feb. 2012.

[32] Department for Strategic Analyses. Chancellery of the Prime Minister of the Republic of Poland, "Optimal energy mix for Poland until 2060 (in Polish), "Warsaw, 2015.

[33] C. De Jonghe, E. Delarue, R. Belmans, and W. D'haeseleer, "Determining optimal electricity technology mix with high level of wind power penetration," Appl. Energy, vol. 88, no. 6, pp. 2231-2238, Jun. 2011.

[34] C. De Jonghe, B. F. Hobbs, and R. Belmans, "Optimal Generation Mix With Short-Term Demand Response and Wind Penetration,” IEEE Trans. Power Syst., vol. 27, no. 2, pp. 830-839, May 2012.

[35] S. Kamalinia and M. Shahidehpour, "Generation expansion planning in wind-thermal power systems," IET Gener. Transm. Distrib., vol. 4, no. 8, p. 940, 2010.

[36] M. Sadeghi and H. Mirshojaeian Hosseini, "Energy supply planning in Iran by using fuzzy linear programming approach (regarding uncertainties of investment costs)," Energy Policy, vol. 34, no. 9, pp. 993-1003, Jun. 2006.

[37] Y. F. Li, Y. P. Li, G. H. Huang, and X. Chen, "Energy and environmental systems planning under uncertainty-An inexact fuzzy-stochastic programming approach," Appl. Energy, vol. 87, no. 10, pp. 3189-3211, Oct. 2010.

[38] Q. Hu, G. Huang, Y. Cai, and Y. Huang, "Feasibility-based inexact fuzzy programming for electric power generation systems planning under dual uncertainties," Appl. Energy, vol. 88, no. 12, pp. 4642-4654, Dec. 2011.

[39] M. Esmaili, E. C. Firozjaee, and H. A. Shayanfar, "Optimal placement of distributed generations considering voltage stability and power losses with observing voltage-related constraints," Appl. Energy, vol. 113, pp. 1252-1260, Jan. 2014.

[40] P. Kayal and C. K. Chanda, "Placement of wind and solar based DGs in distribution system for power loss minimization and voltage stability improvement," Int. J. Electr. Power Energy Syst., vol. 53, pp. 795-809, Dec. 2013.

[41] M. Gitizadeh, A. A. Vahed, and J. Aghaei, "Multistage distribution system expansion planning considering distributed generation using hybrid evolutionary algorithms," Appl. Energy, vol. 101, pp. 655-666, Jan. 2013.

[42] EIA (Energy Information Administration), "Updated Capital Cost Estimates for Utility Scale Electricity Generating Plants," 2013.

[43] EIA (Energy Information Administration), "The Electricity Market Module of the National Energy Modeling System: Model Documentation 2014," 2014.

[44] DIW, "Current and Prospective Costs of Electricity Feneration until 2050. Data Documentation,” 2013.

[45] M. Carrión and J. M. Arroyo, "A computationally efficient mixed-integer linear formulation for the thermal unit commitment problem," IEEE Trans. Power Syst., vol. 21, no. 3, pp. 1371-1378, 2006.

[46] J. M. Arroyo and a. J. Conejo, "Optimal response of a thermal unit to an electricity spot market," IEEE Trans. Power Syst., vol. 15 , no. 3 , pp. $1098-1104,2000$

[47] B. F. Hobbs, M. H. Rothkopf, R. P. O'Neill, and H. Chao, THE NEXT GENERATION OF ELECTRIC POWER UNIT COMMITMENT MODELS. Kluwer Academic Publishers, 2002.

[48] T. Li and M. Shahidehpour, "Price-based unit commitment: A case of Lagrangian relaxation versus mixed integer programming," IEEE Trans. Power Syst., vol. 20, no. 4, pp. 2015-2025, 2005.

[49] C. M. Correa-posada and P. Sánchez-martín, "Integrated Power and Natural Gas Model for Energy Adequacy in Short-Term Operation,” IEEE Trans. Power Syst., vol. 30, no. 6, pp. 3347-3355, 2015.

[50] J. Ostrowski, M. F. Anjos, and A. Vannelli, "Tight Mixed Integer Linear Programming Formulations for the Unit Commitment Problem," IEEE Trans. Power Syst., vol. 27, no. 1, pp. 39-46, 2012.

[51] G. Morales-España, J. M. Latorre, and A. Ramos, "Tight and compact MILP formulation for the thermal unit commitment problem," IEEE Trans. Power Syst., vol. 28, no. 4, pp. 4897-4908, 2013.

[52] PSE S.A. (Polish Transmission System Operator), "Polish Power System Data and Reports," Data and Reports on Polish Power System, 2015.

[53] ARE S.A.(The Energy Market Agency), "Statistics of Polish Power System," 2014.

[54] Supreme Audit Office. Republic of Poland., "Conventional power generation adequacy. Control report /P/14/018/KGP. (in Polish)," Warsaw.

\section{Appendices}

\subsection{Appendix A}

Table 11. Sets meaning

\begin{tabular}{|c|c|c|}
\hline Symbol & Unit & Meaning \\
\hline$c \epsilon\left[1, c t_{u}\right]$ & $\mathrm{yr}$ & Set of indices $c$ representing construction years of generating units $u$. \\
\hline$t \epsilon T$ & $\mathrm{yr}$ & $\begin{array}{l}\text { Set of indices } t \text { representing time periods for time horizon 2020-2050. Single period represents one } \\
\text { year }\end{array}$ \\
\hline$u \epsilon \boldsymbol{U}$ & - & $\begin{array}{l}\text { Set of indices } u \text { representing power generating units. Subsets } U^{\prime} \text { and } U^{\prime \prime}, U^{\prime \prime \prime} \text { denote conventional } \\
\text { CDGUs, hydro CDGUs and RES }\end{array}$ \\
\hline$w \epsilon W$ & - & Set of indices $w$ representing power generating units which can be constructed in the same year $t$ \\
\hline
\end{tabular}


Table 12. Parameters meaning

\begin{tabular}{|c|c|c|}
\hline Symbol & Unit & Meaning \\
\hline A_MAT & - & Matrix of parameters $A_{u^{\prime}, t}(1 / 0)$ \\
\hline B_MAT & - & Matrix of parameters $B_{u^{\prime}, t}(1 / 0)$ \\
\hline $\mathrm{CCO}_{t}$ & $€ / \mathrm{t}$ & $\mathrm{CO}_{2}$ emission allowances price in year $t$ \\
\hline $\mathrm{CCON}_{u}$ & $€ / \mathrm{MW}$ & Construction cost of unit $u$ \\
\hline C_DISP $P_{u, t}$ & $€ / \mathrm{MW} \mathrm{h}$ & Variable costs of operation of unit $u$ in year $t$ \\
\hline CEMCO2 $2_{u, t}$ & $€ / \mathrm{MWh}$ & $\mathrm{CO}_{2}$ emission costs of unit $u$ in period $t$ \\
\hline$C \boldsymbol{F}_{u, t}$ & $€ / \mathrm{MW}$ & Fixed costs of unit $u$ in year $t$ \\
\hline CFIN $_{u, t}$ & $€ / \mathrm{MW}$ & Financial costs of unit $u$ in period $t$ \\
\hline CFUEL $L_{u, t}$ & $€ / \mathrm{MWh}$ & Fuel costs of unit $u$ in period $t$ \\
\hline COMFIX ${ }_{u, t}$ & $€ / \mathrm{MW}$ & Fixed operation and maintenance costs of unit $u$ in period $t$ \\
\hline COMVAR ${ }_{u, t}$ & $€ / \mathrm{MWh}$ & Variable operation and maintenance costs of unit $u$ in period $t$ \\
\hline $\operatorname{COV}_{u}$ & $€ / \mathrm{MW}$ & Overnight cost of unit $u$ \\
\hline$C T_{u}$ & $\mathrm{yr}$ & Construction time of unit $u$ \\
\hline$C V_{u, t}$ & $€ / \mathrm{MWh}$ & Variable costs of unit $u$ in year $t$ \\
\hline$E \_D_{t}$ & MWh & Energy demand in year $t$ \\
\hline$E_{-} N C D G U_{t}$ & MWh & Electricity generation of nCDGUs in year $t$ \\
\hline$E_{-} P R I C E_{t}$ & $€ / \mathrm{MWh}$ & Prospective energy price in year $t$ \\
\hline E_RES_REQUIREMENT $T_{t}$ & MWh & Minimum share of RES in year $t$ \\
\hline EMISS $_{u, t}$ & $\mathrm{t} / \mathrm{MWh}$ & Emission intensity of unit $u$ in year $t$ \\
\hline EMISS_PRIMFUEL $L_{u, t}$ & & $\mathrm{t} / \mathrm{MWh} \quad$ Emission intensity for primary fuel of unit $u$ in year $t$ \\
\hline$I N S_{u}$ & $€ / \mathrm{MW}$ & Instalment of unit $u$ \\
\hline$I N T \_C O N_{u}$ & $€ / \mathrm{MW}$ & Interest of unit $u$ accrued during construction time $C T_{u}$ \\
\hline$I N T_{-} R T_{u, t}$ & $€ / \mathrm{MW}$ & Interest of unit $u$ repaid in year $t$ \\
\hline$K_{-} A_{u, t}$ & $\%$ & Availability factor of unit $u$ in year $t$ \\
\hline$K \_A \_N C D G U_{t}$ & $\%$ & Availability factor of nCDGUs in year $t$ \\
\hline$K_{-} A E X P_{u, c}$ & $\%$ & $\begin{array}{l}\text { Annual expenditures factor of unit } u \text { representing the percent of annual expenditures in construction } \\
\text { year } c\end{array}$ \\
\hline K_DISP $\boldsymbol{u}_{u},{ }^{\prime}, t$ & $\%$ & Dispatched power factor of unit $u$ '”' in year $t$ \\
\hline K_GJMWh & GJ/MWh & Ratio of GJ to MWh \\
\hline$K_{-} P A_{u, t}$ & $\%$ & Power availability factor of unit $u$ in year $t$ \\
\hline K_PA_NCDGU ${ }_{t}$ & $\%$ & Power availability factor of nCDGUs in year $t$ \\
\hline K_PRESERVE $E_{t}$ & $\%$ & Factor of peak load margin in year $t$ \\
\hline$L T_{u}$ & yr & Lifetime of unit $u$ \\
\hline$P \_A_{u, t}$ & MW & Available power of unit $u$ in year $t$ \\
\hline$P \_A \_N C D G U_{t}$ & MW & Available power of nCDGUs in year $t$ \\
\hline$P \_C D G U \_M U S T R U N_{t}$ & MW_h & Required level of must-runs in year $t$ \\
\hline$P_{-} D_{t}$ & MW & Peak load in year $t$ \\
\hline$P \_D I S P \_N C D G U_{t}$ & MW_h & Dispatched power of nCDGUs in year $t$ \\
\hline$P_{-} D I S P \_R E S_{u}{ }^{\prime}, t$ & MW_h & Dispatched power of RES $u$ ', 'in year $t$ \\
\hline$P_{-} I_{u, t}$ & MW & Installed power of unit $u$ in year $t$ \\
\hline$P \_I \_C D G U_{u, t}$ & MW & Installed power of CDGU $u^{\prime}$ in year $t$ \\
\hline P_I_HYDCDGU $U_{u}, t$ & MW & Installed power of hydro CDGU $u$ "' in year $t$ \\
\hline$P \_I \_N C D G U_{t}$ & MW & Installed power of nCDGUs in year $t$ \\
\hline P_I_TOTAL $L_{t}$ & MW & Total installed power in year $t$ \\
\hline$P F U E L_{u, t}$ & $€ / G J$ & Fuel price of unit $u$ in period $t$ \\
\hline$R T_{u}$ & $\mathrm{yr}$ & Repayment time of unit $u$ \\
\hline WACC & $\%$ & Weighted average cost of capital \\
\hline X_DISP_MAT & - & Matrix of binary variables $X_{-} D I S P_{u^{\prime}, t t}$ \\
\hline$X_{-} V E C$ & - & Vector of binary variables $X_{u^{\prime}}$ \\
\hline$Y$ & $\mathrm{~h}$ & Number of hours in a year $(8760)$ \\
\hline Yo_DOWN ${ }_{u, t}$ & MW_h & Downward regulation of tertiary reserve of unit $u$ 'in year $t$ \\
\hline$Y o_{-} U P_{u}, t$ & MW_h & Upward regulation of tertiary reserve of unit $u$ ' in year $t$ \\
\hline$\eta_{u}$ & $\%$ & Efficiency of unit $u$ \\
\hline
\end{tabular}

Table 13. Variables meaning

\begin{tabular}{lll}
\hline Symbol & Unit & Meaning \\
\hline $\boldsymbol{E}_{u, t}$ & MWh & Continuous variables, electricity generation of unit $u$ in year $t$ \\
\hline $\boldsymbol{E}_{-} \boldsymbol{C D G U _ { u } , t}$ & MWh & Continuous variables, electricity generation of CDGU $u$ ' in year $t$ \\
\hline
\end{tabular}




\begin{tabular}{|c|c|c|}
\hline$E_{-} H Y D C D G U_{u}, t, t$ & $\mathrm{MWh}$ & Continuous variables, electricity generation of hydro CDGU $u$ ' ' in year $t$ \\
\hline$E_{-} R E S_{u}, ", t, t$ & MWh & Continuous variables, electricity generation of RES $u$ '”' in year $t$ \\
\hline$P \_D I S P_{u, t}$ & MW_h & Continues variables, dispatched power of unit $u$ in year $t$ \\
\hline$P_{-} D I S P \_C D G U_{u}, t$ & MW_h & Continues variables, dispatched power of CDGU $u^{\prime}$ in year $t$ \\
\hline P_DISP_HYDCDGU $U_{u}, t$ & MW_h & Continues variables, dispatched power of hydro CDGU $u$ "' in year $t$ \\
\hline P_I_HYDCDGU $U_{u, t}$ & MW & Semi-continues variables, installed power of hydro CDGU $u$ "' in year $t$ \\
\hline$P_{-} I_{-} R E S_{u}, \cdots, t$ & MW & Continues variables, installed power of RES $u$ '” in year $t$ \\
\hline$P \_M A X_{u, t}$ & MW_h & Maximum power output of unit $u^{\prime}$ in year $t$ \\
\hline$P \_M I N N_{u}, t$ & MW_h & Minimum power output of unit $u^{\prime}$ in year $t$ \\
\hline PRIMARY_RESERVE $E_{u, t}$ & MW_h & Primary reserve of unit $u^{\prime}$ in year $t$ \\
\hline SECONDARY_RESERVE ${ }_{u}, t$ & MW_h & Secondary reserve of unit $u$ ' in year $t$ \\
\hline$X_{u}$, & - & $\begin{array}{l}\text { Binary variables, if } X_{u} \text { ' equals ' } 1 \text { ", the unit } u \text { ' is constructed and is available in the power system } \\
\text { for period defined by the lifetime. The unit's lifetime and the year of commissioning is included } \\
\text { implicitly in } X_{u} \text { ' }\end{array}$ \\
\hline$X_{-} D I S P_{u}$, & - & $\begin{array}{l}\text { Binary variables, if } X_{-} D I S P_{u^{\prime}, t t} \text { equals " } 1 \text { ", the unit } u \text { ' is dispatched to the operation in peak hour } \\
\text { in year } t \text {. The information about year } t \text { is included implicitly in } X_{-} D I S P_{u^{\prime}}\end{array}$ \\
\hline
\end{tabular}

\subsection{Appendix B}

\subsubsection{Prospective energy demand}

Prospective energy demand is linked with economic growth. Therefore, there is a relation between Gross Domestic Product (GDP) and energy consumption. In $e$ Mix the assumption is overtaken that there will be the energy demand growth by $0.9 \%$ per year which is in relation with $2.5-3 \%$ growth in GDP. The growth in energy demand is also based on historical data and reports made by Polish TSO [52]. Figure 14 presents the assumed forecast ("Energy eMix") and forecasts prepared by national and European entities [32], [53], [54].

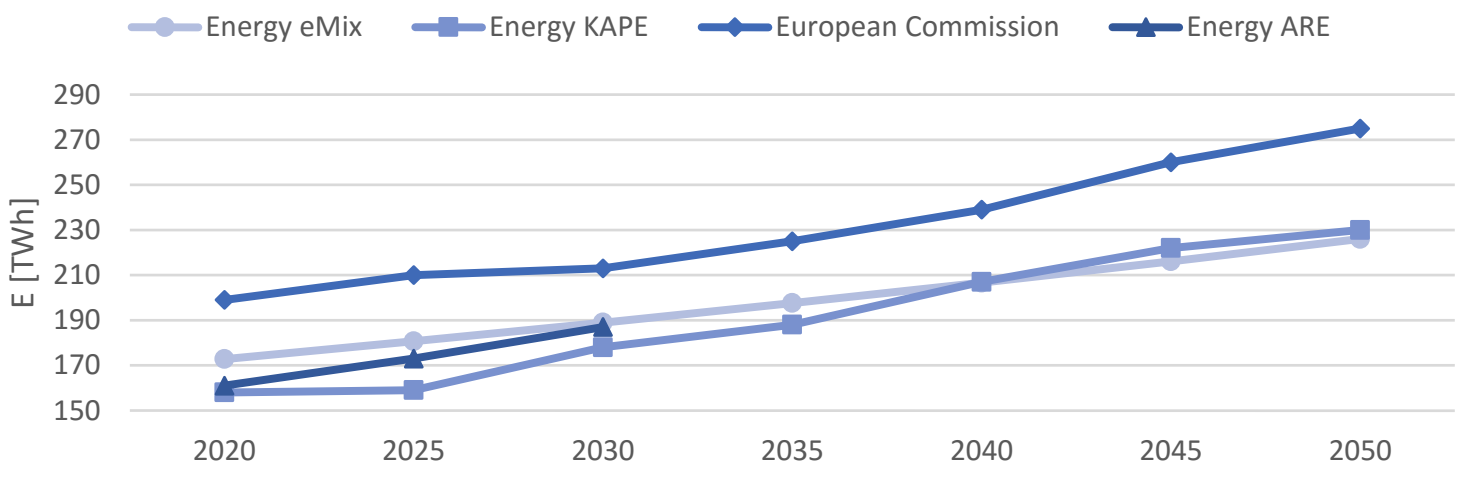

Figure 14. Prospective energy demand

\subsubsection{Prospective peak load}

The forecast for peak load is based on historical data (2001-2015) and the prospective changes in peak load published by Polish TSO in [52]. Such data sources were selected because they based on a) real data from Polish power system and b) forecasting models of Polish TSO. The analysis of the years 2001-2012 shows the annual growth in peak load by $1.6 \%$. However, the last years (2011-2015) indicates lower growth $-1.1 \%-$ and this value has been implemented in the model. It seems to be realistic taking into account the increasing role of energy efficiency and the impact of economic crisis on the national economy.

Table 14. Prospective peak load

\begin{tabular}{ccccc}
\hline Years & $\mathbf{2 0 2 0}$ & $\mathbf{2 0 3 0}$ & $\mathbf{2 0 4 0}$ & $\mathbf{2 0 5 0}$ \\
\hline Peak load $[$ MW] & 27562 & 30748 & 34303 & 38268 \\
\hline
\end{tabular}




\subsubsection{Input parameters}

Table 15. Installed capacity before 2020 in regard to the units' age

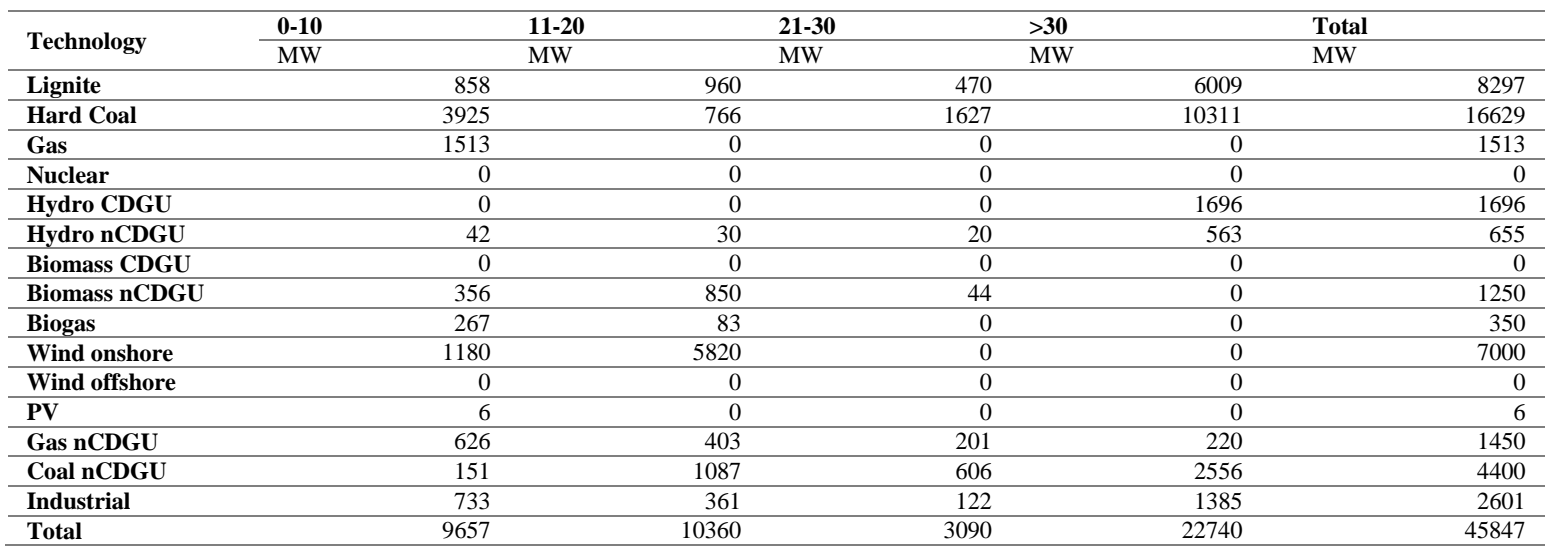

Table 16. Technical parameters

\begin{tabular}{|c|c|c|c|c|c|c|c|c|c|c|c|c|c|}
\hline Technology & : & 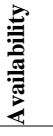 & 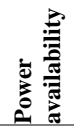 & 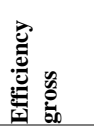 & 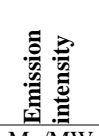 & 节 & 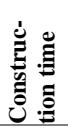 & 产焉 & 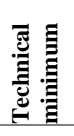 & 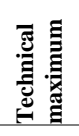 & 递 & 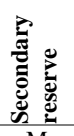 & 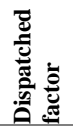 \\
\hline & MW & $\%$ & $\%$ & $\%$ & $\begin{array}{r}\mathrm{Mg} / \mathrm{MW} \\
\mathrm{h}\end{array}$ & $\mathrm{yr}$ & $\mathrm{yr}$ & MW & MW & MW & MW & $\begin{array}{l}\mathrm{M} \\
\mathrm{W}\end{array}$ & $\%$ \\
\hline Lignite existing & $*$ & $\begin{array}{r}84- \\
94 \\
\end{array}$ & 97 & $\begin{array}{r}37- \\
42 \\
\end{array}$ & $\begin{array}{r}0.94- \\
1.07 \\
\end{array}$ & $\begin{array}{r}10- \\
32\end{array}$ & - & - & $\begin{array}{l}94- \\
429 \\
\end{array}$ & $\begin{array}{r}200- \\
832 \\
\end{array}$ & $\begin{array}{l}5- \\
43 \\
\end{array}$ & $\begin{array}{l}0- \\
43\end{array}$ & - \\
\hline Lignite new & $\begin{array}{l}450 \\
900\end{array}$ & 85 & 97 & 42 & 0.94 & 40 & 5 & 2700 & $\begin{array}{l}225 \\
450\end{array}$ & $\begin{array}{l}437 \\
873 \\
\end{array}$ & $\begin{array}{l}18 \\
36 \\
\end{array}$ & $\begin{array}{l}18 \\
36 \\
\end{array}$ & - \\
\hline Hard coal exis. & * & $\begin{array}{r}84- \\
94\end{array}$ & 97 & $\begin{array}{r}37- \\
46\end{array}$ & $\begin{array}{r}0.73- \\
0.91\end{array}$ & $\begin{array}{c}2- \\
41\end{array}$ & - & - & $\begin{array}{l}33- \\
376\end{array}$ & $\begin{array}{r}92- \\
104 \\
2\end{array}$ & $\begin{array}{c}0- \\
43\end{array}$ & $\begin{array}{r}10- \\
54\end{array}$ & - \\
\hline Hard coal new & $\begin{array}{l}450 \\
900 \\
\end{array}$ & 85 & 97 & 46 & 0.73 & 40 & 5 & 3600 & $\begin{array}{l}280 \\
315 \\
\end{array}$ & $\begin{array}{l}437 \\
873 \\
\end{array}$ & $\begin{array}{l}10 \\
36 \\
\end{array}$ & $\begin{array}{l}22 \\
45 \\
\end{array}$ & - \\
\hline Gas existing & $*$ & 94 & 97 & 55 & 0.39 & $\begin{array}{r}21- \\
22\end{array}$ & - & - & $\begin{array}{l}90- \\
120\end{array}$ & $\begin{array}{r}437- \\
582\end{array}$ & $\begin{array}{r}50- \\
66\end{array}$ & $\begin{array}{r}68- \\
90\end{array}$ & - \\
\hline Gas new & 450 & 85 & 97 & 55 & 0.39 & 40 & 3 & 2250 & 90 & 437 & 50 & 68 & - \\
\hline Nuclear & $\begin{array}{r}100 \\
0 \\
160 \\
0 \\
\end{array}$ & 85 & 97 & $\begin{array}{l}35 \\
36\end{array}$ & 0 & 40 & 7 & 2600 & $\begin{array}{l}200 \\
320\end{array}$ & $\begin{array}{r}970 \\
155 \\
2\end{array}$ & 0 & $\begin{array}{l}20 \\
32\end{array}$ & - \\
\hline Hydro & $* *$ & $\begin{array}{l}10 \\
15 \\
\end{array}$ & 70 & - & 0 & 80 & 2 & 1000 & $\begin{array}{l}5- \\
10 \\
\end{array}$ & $\begin{array}{c}70- \\
140\end{array}$ & $\begin{array}{l}5- \\
10\end{array}$ & $\begin{array}{r}20- \\
40\end{array}$ & $\begin{array}{r}* * * * \\
*\end{array}$ \\
\hline Biomass & $* * *$ & 74 & 60 & 32 & 1.23 & 30 & 1 & 600 & $\begin{array}{l}40 \\
80 \\
\end{array}$ & $\begin{array}{r}60 \\
120 \\
\end{array}$ & 0 & $\begin{array}{l}4 \\
8 \\
\end{array}$ & $\begin{array}{r}* * * * \\
* \\
\end{array}$ \\
\hline Biogas & $\begin{array}{r}* * * \\
*\end{array}$ & 40 & 60 & 40 & 0.68 & 30 & 1 & 250 & - & - & - & - & 60 \\
\hline Wind onshore & $\begin{array}{r}* * * \\
*\end{array}$ & 25 & 10 & - & 0 & 25 & 1 & 2000 & - & - & - & - & 20 \\
\hline Wind offshore & $\begin{array}{r}* * * \\
*\end{array}$ & 45 & 10 & - & 0 & 25 & 2 & 500 & - & - & - & - & 20 \\
\hline PV & $\begin{array}{r}* * * \\
*\end{array}$ & 15 & 0 & - & 0 & 15 & 1 & 500 & - & - & - & - & 0 \\
\hline
\end{tabular}

* presented in Table 15; ** hydro CDGUs capacity is in range 100-200MW for single unit, while hydro nCDGUs are unrestricted; *** biomass CDGUs capacity equals 100 MW or 200 MW for single unit, while biomass nCDGUs are unrestricted; **** unrestricted; $* * * * *$ for nCDGUs the dispatched factor is equal to power availability factor.

Table 17. Primary fuel parameters

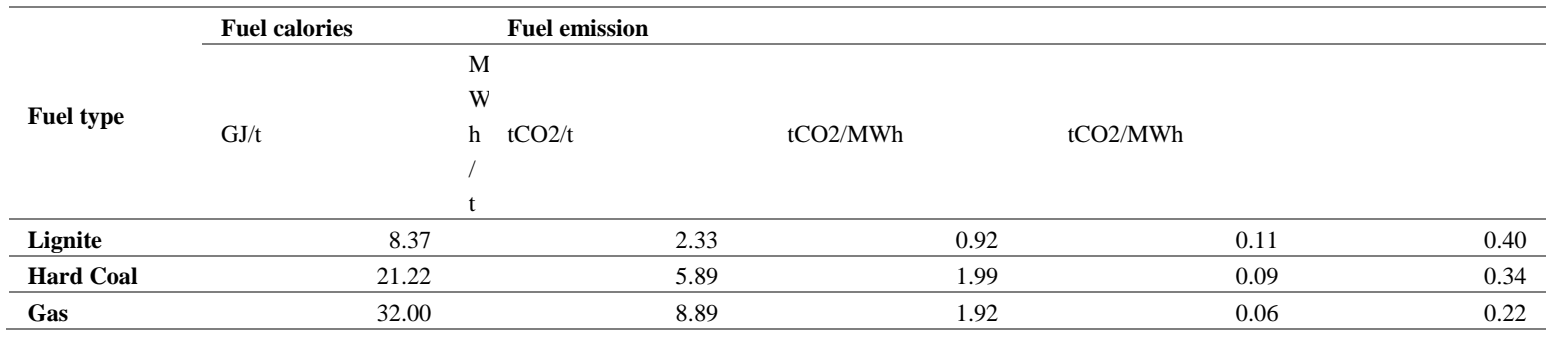


Applied Energy

\begin{tabular}{lrrrrr}
\hline Biomass & 15.59 & 4.33 & 1.71 & 0.11 & 0.39 \\
\hline Biogas & 36.11 & 10.03 & 2.74 & 0.08 & 0.27 \\
\hline
\end{tabular}

Table 18. Financial parameters

\begin{tabular}{|c|c|c|c|c|c|c|c|}
\hline Technology & $\begin{array}{l}\text { Overnight } \\
\text { cost }\end{array}$ & $\begin{array}{l}\text { Fixed } \\
\text { O\&M cost }\end{array}$ & $\begin{array}{l}\text { Variable } \\
\text { O\&M } \\
\text { cost }\end{array}$ & Fuel cost & $\begin{array}{l}\text { Total } \\
\text { financial cost }\end{array}$ & $\begin{array}{l}\text { Repayment } \\
\text { time }\end{array}$ & $\begin{array}{l}\text { Annual } \\
\text { expenditures }\end{array}$ \\
\hline & $\mathrm{mln} € / \mathrm{MW}$ & $€ / M W$ & $€ / \mathrm{MWh}$ & $€ / \mathrm{MWh}$ & $\begin{array}{l}\operatorname{mln} € \\
(\mathrm{mln} € / \mathrm{MW})\end{array}$ & $\mathrm{yr}$ & $\%$ \\
\hline Lignite existing & - & 27900 & 3.3 & $14-18$ & $113-2978$ & lifetime & - \\
\hline Lignite new & $1.58-1.76$ & 27900 & 3.3 & $14-16$ & $2584 ; 4669$ & 40 & $10 / 20 / 30 / 30 / 10$ \\
\hline $\begin{array}{l}\text { Hard coal exist- } \\
\text { ing }\end{array}$ & 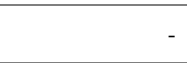 & 27900 & 3.3 & $21-26$ & $7-4859$ & lifetime & 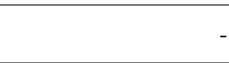 \\
\hline Hard coal new & $1.56-1.65$ & 27900 & 3.3 & 21 & $2432 ; 4604$ & 3 & $10 / 20 / 30 / 30 / 10$ \\
\hline Gas existing & - & 25833 & 2.7 & $*$ & 709-765 & lifetime & - \\
\hline Gas new & 0.66 & 25833 & 2.7 & $*$ & 901 & 40 & $15 / 40 / 45$ \\
\hline Nuclear & $5.54-5.61$ & 95952 & 3.1 & 11 & $95952 ; 103333$ & 40 & $5 / 10 / 20 / 25 / 15 / 15 / 10$ \\
\hline Hydro & 4.45 & 119047 & 2.9 & 0 & $(13.3-13.4)$ & 40 & $70 / 30$ \\
\hline Biomass & 2.33 & 73810 & 3.9 & 62 & $566 ; 1132$ & 30 & 100 \\
\hline Biogas & 3.71 & 142857 & 4.1 & 332 & (9) & 30 & 100 \\
\hline Wind onshore & 1.45 & 26191 & 0 & 0 & (3.2) & 25 & 100 \\
\hline Wind offshore & 3.09 & 123810 & 0 & 0 & (7.2) & 25 & 100 \\
\hline PV & 1.71 & 18571 & 0 & 0 & (3) & 15 & 100 \\
\hline
\end{tabular}

* included in simulation scenarios

Table 19. Weighted average cost of capital (WACC) elements

\begin{tabular}{ccccc}
\hline Loan & Equity & Leverage & WACC \% & $\%$ \\
\hline$\%$ & $\%$ & - & 8.05 & \\
\hline 7 & 10.5 & 0.7 & \\
\hline
\end{tabular}

\subsection{Appendix $C$}

Table 20. Available power by technology, year and scenario

\begin{tabular}{|c|c|c|c|c|c|c|c|c|c|c|c|c|c|c|c|c|c|}
\hline \multicolumn{2}{|c|}{ Technology } & 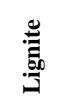 & 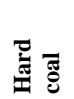 & Eี & $\frac{\ddot{z}}{\tilde{z}}$ & 题 & 월용 & Oئ & 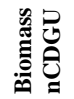 & $\underset{0}{0}$ & 竞 & 递 & $z$ & 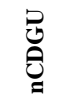 & 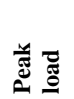 & 吾 & 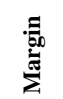 \\
\hline & & & & & & & 70 & & & & 8 & & & 8 & $0 \mathrm{w}$ & & $\%$ \\
\hline \multirow{4}{*}{ S1 } & $\begin{array}{l}202 \\
0\end{array}$ & 23 & 47 & 7 & 0 & 3 & 1 & 0 & 3 & 1 & 2 & 0 & 0 & 12 & 27.6 & 34.5 & 25 \\
\hline & $\begin{array}{l}203 \\
0\end{array}$ & 30 & 33 & 15 & 0 & 3 & 1 & 0 & 3 & 1 & 3 & 0 & 0 & 11 & 30.7 & 36.6 & 19 \\
\hline & $\begin{array}{l}204 \\
0 \\
\end{array}$ & 24 & 14 & 43 & 0 & 3 & 1 & 0 & 2 & 1 & 4 & 0 & 0 & 10 & 34.3 & 42.8 & 25 \\
\hline & $\begin{array}{l}205 \\
0\end{array}$ & 26 & 8 & 50 & 0 & 2 & 1 & 0 & 0 & 0 & 4 & 0 & 0 & 8 & 38.3 & 48.4 & 26 \\
\hline \multirow{4}{*}{ S2 } & $\begin{array}{l}202 \\
0\end{array}$ & 23 & 47 & 7 & 0 & 3 & 1 & 0 & 3 & 1 & 2 & 0 & 0 & 12 & 27.6 & 34.5 & 25 \\
\hline & $\begin{array}{l}203 \\
0\end{array}$ & 20 & 32 & 27 & 0 & 3 & 1 & 0 & 2 & 1 & 3 & 0 & 0 & 11 & 30.7 & 37.9 & 23 \\
\hline & $\begin{array}{l}204 \\
0\end{array}$ & 5 & 13 & 64 & 0 & 3 & 1 & 0 & 2 & 1 & 3 & 0 & 0 & 9 & 34.3 & 45.4 & 32 \\
\hline & $\begin{array}{l}205 \\
0\end{array}$ & 3 & 8 & 75 & 0 & 2 & 1 & 0 & 0 & 0 & 4 & 0 & 0 & 8 & 38.3 & 51.0 & 33 \\
\hline \multirow{4}{*}{$\mathbf{S 3}$} & $\begin{array}{l}202 \\
0\end{array}$ & 23 & 47 & 7 & 0 & 3 & 1 & 0 & 3 & 1 & 2 & 0 & 0 & 12 & 27.6 & 34.5 & 25 \\
\hline & $\begin{array}{l}203 \\
0 \\
\end{array}$ & 20 & 32 & 26 & 0 & 3 & 1 & 0 & 2 & 1 & 3 & 0 & 0 & 11 & 30.7 & 37.5 & 22 \\
\hline & $\begin{array}{l}204 \\
0 \\
\end{array}$ & 5 & 20 & 56 & 0 & 3 & 1 & 0 & 2 & 1 & 3 & 0 & 0 & 9 & 34.3 & 44.1 & 28 \\
\hline & $\begin{array}{l}205 \\
0\end{array}$ & 3 & 16 & 67 & 0 & 2 & 1 & 0 & 0 & 0 & 4 & 0 & 0 & 8 & 38.3 & 50.1 & 31 \\
\hline \multirow{4}{*}{ S4 } & $\begin{array}{l}202 \\
0\end{array}$ & 22 & 45 & 10 & 0 & 3 & 1 & 0 & 3 & 1 & 2 & 0 & 0 & 12 & 27.6 & 35.8 & 30 \\
\hline & $\begin{array}{l}203 \\
0 \\
\end{array}$ & 20 & 32 & 27 & 0 & 3 & 1 & 0 & 2 & 1 & 3 & 0 & 0 & 11 & 30.7 & 37.9 & 23 \\
\hline & $\begin{array}{l}204 \\
0 \\
\end{array}$ & 5 & 13 & 64 & 0 & 3 & 1 & 0 & 2 & 1 & 3 & 0 & 0 & 9 & 34.3 & 45.4 & 32 \\
\hline & $\begin{array}{l}205 \\
0 \\
\end{array}$ & 3 & 8 & 75 & 0 & 2 & 1 & 0 & 0 & 0 & 4 & 0 & 0 & 8 & 38.3 & 51.0 & 33 \\
\hline
\end{tabular}


Table 21. Energy generation by technology, year and scenario

\begin{tabular}{|c|c|c|c|c|c|c|c|c|c|c|c|c|c|c|c|}
\hline \multicolumn{2}{|c|}{ Technology } & 苟 & స్ట & שี & 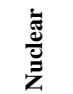 & $\begin{array}{l}0 \\
0 \\
0\end{array}$ & 号 & 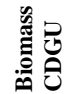 & 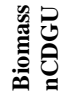 & 量 & $\frac{0}{\frac{0}{0}}$ & 竎 & 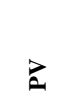 & 己ે & 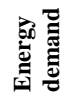 \\
\hline & & $\%$ & $\%$ & $\%$ & $\%$ & $\%$ & $\%$ & $\%$ & $\%$ & $\%$ & $\%$ & $\%$ & $\%$ & $\%$ & TWh \\
\hline \multirow{4}{*}{ S1 } & 2020 & 36 & 26 & 3 & 0 & 0 & 0 & 0 & 6 & 1 & 10 & 1 & 0 & 17 & 173 \\
\hline & 2030 & 41 & 20 & 4 & 0 & 1 & 0 & 0 & 4 & 0 & 13 & 1 & 0 & 16 & 189 \\
\hline & 2040 & 39 & 17 & 10 & 0 & 1 & 0 & 0 & 1 & 0 & 16 & 1 & 0 & 15 & 207 \\
\hline & 2050 & 43 & 15 & 10 & 0 & 1 & 0 & 0 & 0 & 0 & 18 & 0 & 0 & 14 & 226 \\
\hline \multirow{4}{*}{ S2 } & 2020 & 29 & 25 & 11 & 0 & 0 & 0 & 0 & 6 & 1 & 10 & 1 & 0 & 17 & 173 \\
\hline & 2030 & 9 & 20 & 36 & 0 & 1 & 0 & 0 & 4 & 0 & 13 & 1 & 0 & 16 & 189 \\
\hline & 2040 & 6 & 16 & 44 & 0 & 1 & 0 & 0 & 1 & 0 & 16 & 1 & 0 & 15 & 207 \\
\hline & 2050 & 5 & 14 & 48 & 0 & 1 & 0 & 0 & 0 & 0 & 18 & 0 & 0 & 14 & 226 \\
\hline \multirow{4}{*}{ S3 } & 2020 & 36 & 26 & 3 & 0 & 0 & 0 & 0 & 6 & 1 & 10 & 1 & 0 & 17 & 173 \\
\hline & 2030 & 8 & 20 & 37 & 0 & 1 & 0 & 0 & 3 & 1 & 13 & 1 & 0 & 16 & 189 \\
\hline & 2040 & 7 & 28 & 31 & 0 & 1 & 0 & 0 & 0 & 1 & 16 & 1 & 0 & 15 & 207 \\
\hline & 2050 & 5 & 28 & 35 & 0 & 1 & 0 & 0 & 0 & 0 & 18 & 0 & 0 & 14 & 226 \\
\hline \multirow{4}{*}{ S4 } & 2020 & 9 & 39 & 17 & 0 & 0 & 0 & 0 & 6 & 1 & 10 & 1 & 0 & 17 & 173 \\
\hline & 2030 & 5 & 20 & 40 & 0 & 1 & 0 & 0 & 3 & 1 & 13 & 1 & 0 & 16 & 189 \\
\hline & 2040 & 2 & 16 & 48 & 0 & 1 & 0 & 0 & 0 & 1 & 16 & 1 & 0 & 15 & 207 \\
\hline & 2050 & 1 & 14 & 52 & 0 & 1 & 0 & 0 & 0 & 0 & 18 & 0 & 0 & 14 & 226 \\
\hline
\end{tabular}

